\title{
Evolution of South American Paucituberculata (Metatheria: Marsupialia): adaptive radiation and climate changes at the Eocene- Oligocene boundary
}

\author{
María Alejandra Abello ${ }^{a}$ Nestor Toledo ${ }^{b}$ and Edgardo Ortiz-Jaureguizar ${ }^{\mathrm{a}}$
}

aFacultad de Ciencias Naturales y Museo (UNLP), Laboratorio de Sistemática y Biología Evolutiva (LASBE), Unidades de investigación Anexo Museo, La Plata, Argentina; ${ }^{b}$ Facultad de Ciencias Naturales y Museo (UNLP), División Paleontología de Vertebrados, Unidades de investigación Anexo Museo, La Plata, Argentina

\begin{abstract}
The Eocene-Oligocene boundary (EOB) marks a period of remodeling in the metatherian faunas of South America. Paucituberculata was one of the groups that successfully diversified as the climate and environment conditions changed, and they became, during the first part of the Neogene, an important component of micromammal assemblages. Among paucituberculatans, the non-pichipilid palaeothentoids (NPP) has been recognized as the clade that diversified most widely in post-EOB times. Here we explore the evolutionary response of the NPP to the climatic-environmental changes around the EOB, by analysing the temporal patterns of disparity, taxonomic diversity and body mass in a phylogenetic context. To asses the magnitude of the NPP radiation comparisons based on these macroevolutionary parameters were done with its sister-group Pichipilidae, and its next closest relative, the Caenolestidae. In all considered parameters, NPP reached values significantly higher than the remaining paucituberculatans clades. From its initial diversification in the middle Eocene, taxonomic diversity increased through time, but it was decoupled from disparity across the EOB, and from the late Oligocene to early Miocene. The Oligocene emerges as the key period in NPP evolution, which is evidenced by a significant and concordant expansion of disparity and taxonomic diversity, suggesting evolution into empty ecospace.
\end{abstract}

\section{ARTICLE HISTORY}

Received 9 January 2018

Accepted 16 July 2018

\section{KEYWORDS}

Cenozoic; disparity; diversity; body size; marsupials

\section{Introduction}

Metatherians (crown-clade Marsupialia plus their stem relatives; Rougier et al. 1998) evolved in South America throughout Cenozoic, achieving an important taxonomic and ecological diversity (Goin et al. 2016). Paucituberculata, Sparassodonta, Didelphimorphia, Microbiotheria, Polydolopimorphia, as well as diverse 'basal ameridelphians' (e.g., Pucadelphyidae and Protodidelphidae, Oliveira and Goin 2011) are among the main groups currently recognized that occurred in this continental area. From one or more immigrants lineages from North America, probably in a late Cretaceous - earliest Paleocene dispersal event (Pascual and Ortiz-Jaureguizar 2007; Goin et al. 2012; Woodburne et al. 2014), metatherians radiated in South America, occupying a wide range of ecological roles such as small $(<100 \mathrm{~g})$ to medium $(100 \mathrm{~g}-500 \mathrm{~g})$ insectivores, omnivores and frugivores (didelphimorphians, microbiotherians, polydolopimorphians and paucituberculatans; Zimicz 2011, 2014; Abello et al. 2012), and small $(<7 \mathrm{~kg}$ ) to large (above $15 \mathrm{~kg}$ ) mesocarnivores and hypercarnivores (sparassodonts; Prevosti et al. 2013). The evolutionary history of these groups was marked by the impact of deep climatic and environmental changes, both global and regional, which appears to have driven major macroecological processes, such as radiations, extinctions and turnovers (Pascual and Ortiz-Jaureguizar 2007; Goin et al. 2012, 2016). For living marsupials, it has been stated that ambient temperature strongly influence several of their life history variables, such as feeding preferences, reproductive strategies and distribution (see Goin et al. 2016). At a large temporal-scale, global temperature variations over the Cenozoic such as warming and cooling trends and thermal spikes (e.g. the Mid-Eocene Climatic Optimum, c.a. 42Myr BP; Hansen et al. 2013) appears to have been closely related to the major changes in the evolution of South American groups (Goin et al. 2010, 2016). Atlantic transgressions and regressions, such as those of the Paleocene and Miocene (Malumian and Nañez 2011), together with the Andean uplift, were among the major geological events that shaped the paleogeography of South America, having effects on regional climate and landscape evolution (Ortiz-Jaureguizar and Cladera 2006; Ramos and Ghiglione 2008; Hoorn et al. 2010). There were the isolation of Antarctica and the formation of the Antarctic Circumpolar Current, with consequent drops of global temperatures near the Eocene-Oligocene boundary (EOB), the geological and climatic events that deeply affected metatherian assemblages of South America (Goin et al. 2010, 2016). At that time, metatherian fauna suffered a large turnover, with many lineages becoming extinct (e.g. basal 'ameridelphians' and polydolopid polydolopimorphians) and others radiating (e.g. pacituberculatans and sparassodonts) (Goin et al. 2010, 2016).

Having arose in the early Eocene at the latest, and survived into the present, paucituberculatans are one of the oldest surviving lineages of South American metatherians. Thus, throughout the last 50 M.a., their evolution is likely to have

CONTACT María Alejandra Abello mabello@fcnym.unlp.edu.ar $\Theta$ Facultad de Ciencias Naturales y Museo (UNLP), Laboratorio de Sistemática y Biología Evolutiva (LASBE), Unidades de investigación Anexo Museo. Av. 60 y 122. B1900FWA, La Plata, Argentina 
been strongly influenced by diverse environmental changes such as those mentioned above. In fact, the EOB climatic event appears to have marked a turning point in their evolutionary history (Abello 2013; Abello et al. 2015).

Paucituberculatans are currently grouped into two main clades: Caenolestoidea, which includes the extant shrew opossums and their extinct relatives (Caenolestidae), and Palaeothentoidea, which groups the remaining extinct paucituberculatans into three main clades, Pichipilidae, Abderitidae and Palaeothentidae (Goin et al. 2009; Abello 2013; Rincón et al. 2015; Engelman et al. 2016). The caenolestids are generalized species, small sized, mostly insectivorous and terrestrials (Kirsch and Waller 1979; Patterson and Gallardo 1987; Martin and González-Chávez 2016; Figure 1A). On the other hand, the palaeothentoids includes the most specialized paucituberculatans, some of them dentally convergent on diprotodontian

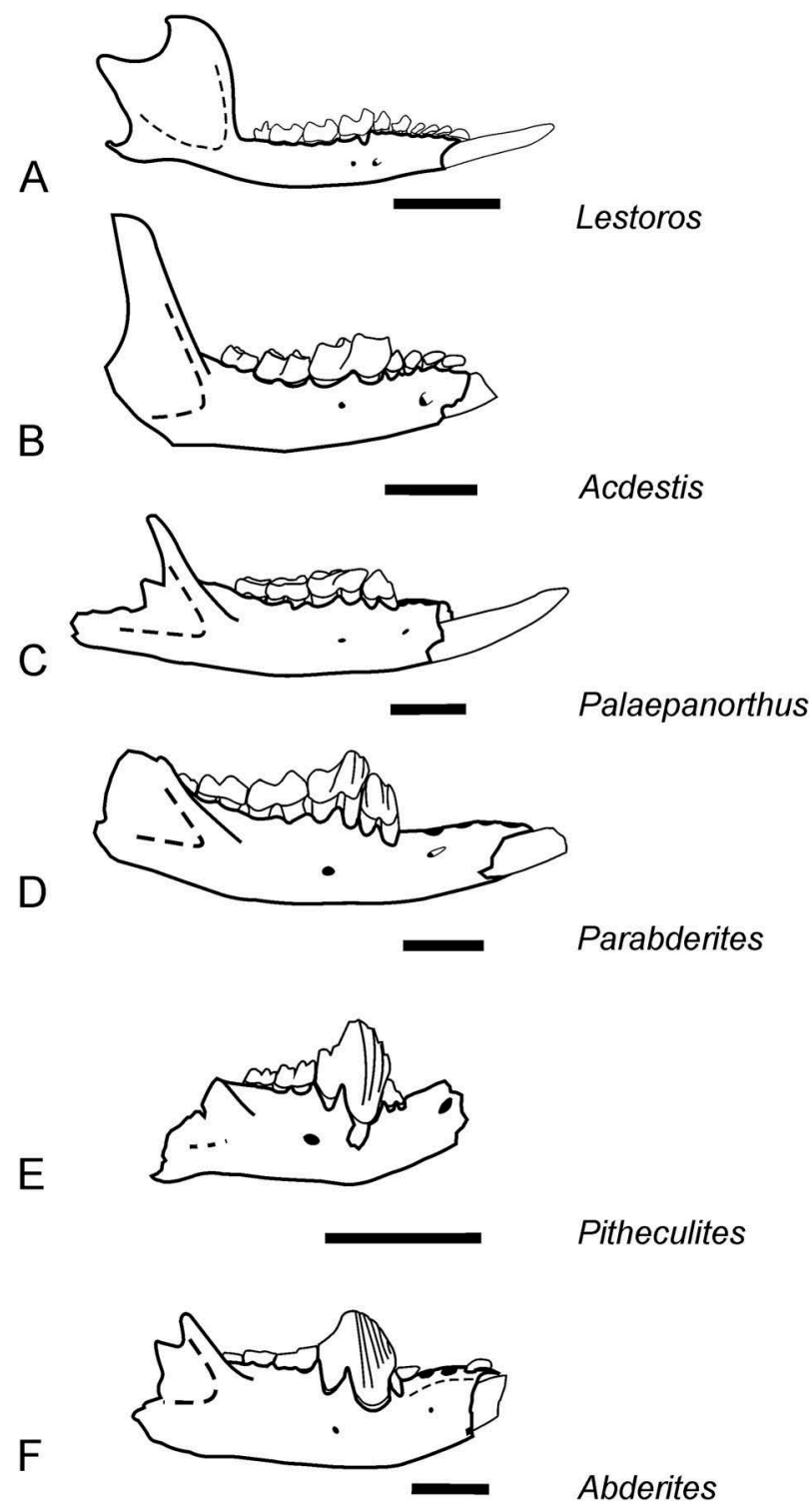

Figure 1. Comparative paucituberculatan mandible and lower dental morphology. Schematic drawings are based on the following specimens: A, USNM 194,383 (Lestoros inca); B, MACN 2038 and MACN 5560 (Acdestis spegazzinii); C, MLP 82-V-2-108 (Palaepanorthus primus); D, MPEF-PV 5834 (Parabderites bicrispatus); E, MPEF-PV 5833 (Pitheculites minimus); F, MPEF-PV 5847 (Abderites crispus). Scale bar $=5 \mathrm{~mm}$. marsupials (burramyds and petaurids; Marshall 1980; OrtizJaureguizar 2003). In particular, the abderitids developed a plagiaulacoid dentition (i.e., one or more teeth transformed into large laterally compressed blades with cutting serrated margins (Simpson 1933; Figure 1D-F) similarly developed in certain multituberculates (e.g., the cimolodontan Ptilodus), primates (e.g., Carpodaptes) and diprotodontians (e.g., potoroids and Burramys). Studies on diet and body size indicated that the non-pichipilid palaeothentoids (NPP) were diverse, including small- to medium-sized insectivores, medium-sized frugivores and small- to -large-sized ( $>500 \mathrm{~g}$ ) insectivore-frugivore species (Dumont et al. 2000; Abello et al. 2012; Zimicz 2012). It was proposed that this diversity, both ecological and taxonomic, expanded near the $\mathrm{EOB}$ in association with the climatic-environmental changes that took place in South America after the separation from Antarctica (Goin et al. 2010; Abello 2013; Rincón et al. 2015), but the key features of this radiation have only been subject to preliminary analyses (Abello et al. 2015, 2016). Studies on adaptive radiations state that significant increases in taxonomic and morphological diversity (disparity sensu Foote 1993a) occur as a lineage diversifies into different ecological niches (Simpson 1953; Foote 1994; Schluter 2000), and different models of radiations have been proposed depending on the relationships between both components of diversity (Foote 1993b; Benton et al. 2014). Large-scale, temporal patterns of disparity and taxonomic diversity are critical to understanding the macroevolutionary processes involved in generating biodiversity (Foote 1994, 1997; Erwin 2007). In addition, because body size its an important predictor of species ecology, as it is correlated with a host of biological variables (Damuth and MacFadden 1990), the analysis of its evolution can account for the pattern of niche occupation during diversification.

The main purpose of this contribution is to analyze the evolution of the NPP clade in terms of taxonomic diversity, disparity and body mass evolution (used as a proxy for body size), and to evaluate how climatic-environmental changes at the EOB could have be related to the observed pattern of changes in these macroecological parameters. Additionally, comparisons based on these evolutionary aspects will be done with their sister-group Pichipilidae, and its next closest relative, the Caenolestidae (Abello 2013). We expect that our results will allow a better understanding on paucituberculatan macroevolution, and contribute to future studies on mammal community interactions and biodiversity construction during the Cenozoic of South America.

\section{Material and methods}

Extinct paucituberculatan species are mainly known from fragmentary cranial remains, such as mandibles, maxillae and isolated upper and lower teeth, while postcranial and more complete cranial remains are scarce (Abello \& Candela 2010; Forasiepi et al. 2014; Figure 1). Thus, phylogenetic relationships of paucituberculatans, as well as aspects of their paleobiology, such as diet and body mass, have been mainly inferred from dental morphology (Dumont et al. 2000; Abello et al. 2012; Zimicz 2012; Abello 2013; Rincón et al. 2015; Engelman et al. 2016). Here we present a revised phylogeny of the group, and body mass estimations for most 
paucituberculatan species. The new hypothesis is used as a phylogenetic context to analyze body size evolution, and changes in diversity, disparity and morphospace occupation of the NPP during their Eocene-to-Miocene radiation.

\section{Abbreviations}

\section{Species acronyms}

Aaisen, Abderites aisenense; Acrispus, Abderites crispus; Aclemai, Acdestis lemairei; Acmad, Acdestis maddeni; Acowenii, Acdestis owenii; Aili, Antawallathentes illimani; Ameridio, Abderites meridionalis; Aquimsa, Antawallathentes quimsacruza; Bardh, Bardalestes hunco; Bardsp, Bardalestes sp.; Cae, Caenolestes fuliginosus; Cchubu, Carlothentes chubutensis; Evoh, Evolestes hadrommatos; Evosp, Evolestes sp.; Fsorex, Fieratherium sorex; Lest, Lestoros inca; nov. 1, Sp. nov 1; nov. 2, Sp. nov 2; nov. 3, Sp. nov 3; nov. 4, Sp. nov 4; nov. 5, Sp. nov 5; Palara, Palaeothentes aratae; Palinter, Palaeothentes intermedius; Pallem, Palaeothentes lemoinei; Palmarsh, Palaeothentes marshalli; Palmigue, Palaeothentes migueli; Palmin, Palaeothentes minutus; Palpas, Palaeothentes pascuali; Palpri, Palaepanorthus primus; Palreli, Palaeothentes relictus; Palserra, Palaeothentes serratus; Pbicris, Parabderites bicrispatus; Pboli, Palaeothentes boliviensis; Pcard, Perulestes cardichi; Pcent, Pichipilus centinelus; Pchenche, Pitheculites chenche; Pfrai, Perulestes fraileyi; Phono, Phonocdromus gracilis; Pilan, Pilchenia antiqua; Pilinter, Pilchenia intermedia; Pilu, Pilchenia lucina; Pminimus, Pitheculites minimus; Pminus, Parabderites minusculus; Posbor, Pichipilus osborni; Prig, Pichipilus riggsi; Prothi, Pitheculites rothi; Ptrip, Pliolestes tripotamicus; Pven, Pliolestes venetus; Quiroga, Quirogalestes almagaucha; Rhyn, Rhyncholestes raphanurus; Rio, Riolestes capricornicus; Stilo, Stilotherium dissimile; Sasa, Sasawatsu mahaynaq; Trothi, Trelewthentes rothi; Tsimp, Titanothentes simpsoni; Titano. Titanothentes sp.

\section{Institutional abbreviations}

MACN-A, Museo Argentino de Ciencias Naturales 'Bernardino Rivadavia' (Ameghino collection), Ciudad Autónoma de Buenos Aires, Argentina; MLP, Museo de La Plata, La Plata, Argentina; MPEF-PV, Museo Paleontológico Egidio Feruglio (palaeovertebrate collection), Trelew, Argentina; USNM, United States National Museum, Smithsonian Institution, Washington, D.C., United States.

\section{Dietary habits and body size of paucituberculatans}

For dietary categories (i.e., frugivore, insectivore-frugivore and insectivore) and body size categories (i.e., small $<100 \mathrm{~g}$, medium $=100 \mathrm{~g}-500 \mathrm{~g}$, large $>500 \mathrm{~g})$ used in this work, see discussion in Abello et al. (2012).

\section{Paucituberculatan phylogeny and temporal calibration}

The revised phylogeny of paucituberculatans is based on a data matrix modified from those of earlier works (Abello 2013; Rincón et al. 2015; Engelman et al. 2016). As in the analysis of Abello
(2013), a reduced matrix was constructed from a total matrix (SM1) consisting of 63 species and 82 discrete cranio-dental characters by the removal of three problematic taxa (SM2). Both matrices were subjected to a cladistic analysis using maximum parsimony, as implemented in TNT 1.5-beta (Goloboff et al. 2003). The search parameters to recover the most parsimonious trees are detailed in the SM2. Multiple most parsimonious trees were summarised using strict consensus.

To obtain a timescaled phylogeny, we followed the methodology of Brusatte et al. (2008a) and Lloyd (2016). We applied the command timePaleoPhy from the $\mathrm{R}$ package paleotree (Bapst 2012), set with the 'equal' method corresponding to that used in Brusatte et al. (2008a). This method proceeds by increasing the root divergence time by a predefined amount and then adjusting the zero-length branches in such a way that time on early branches is re-apportioned out along those later branches equally. Branches times were adjusted in order relative to the number of nodes separating the edge from the root, going from the shallowest branches to the deepest branches. For terminal taxa (cladogram tips), we used the absolute ages detailed in SM3, depicted as ranges between a First Appearance Date (FAD) and a Last Appearance Date (LAD). When no ranges were available, we introduced an extremely close hypothetical LAD of 10,000 years more recent than the actual age datum. Given the limitations of our dataset, we preferred this method instead of others, more sophisticated ones such as the 'cal3' by Bapst (2012), because we purposely intended to minimize the number of assumptions involved in the model, therefore decreasing the incertainty introduced by modelization (for example estimation of branching and extinction rates). In addition, some nodes were dated taking into account additional information from the fossil record. Such is the case of the records of Perulestes sp. and Sasawatsu sp. in the middle Eocene of Peru (Antoine et al. 2016) which places the origins of the NPP clade at a minimum age of $41 \mathrm{Ma}$ ago, the records of an Acdestinae indet. in the late Oligocene of Patagonia (Bown and Fleagle 1993; Abello 2007), placing the origin of Acdestinae clade at least at $27.75 \mathrm{Ma}$., and Abderites sp. in the late Oligocene of Peru (Antoine et al. 2016) placing the origin of the Abderites clade at least at $26.56 \mathrm{Ma}$. ago. The absolute ages of terminal taxa, as well as references about their geographic and temporal distribution, are shown in SM3.

\section{Taxonomic diversity through time}

Previous analyses of paucituberculatan taxonomic diversity were based on a simple counting of the stratigraphic record of species during discrete intervals of time (e.g., Abello 2013; Rincón et al. 2015; Engelman et al. 2016). This traditional taxic approach leads to underestimate of the age of clades and palaeodiversity (Norell 1993; Lane et al. 2005). Therefore, in order to enhance taxonomic richness measures we estimated the diversity as predicted by phylogeny, using a calibrated phylogeny of paucituberculatans (see above) and correcting observed temporal ranges of taxa by considering ghost lineages (Norell 1992, 1993).

For the NPP, diversity was calculated for four time bins of comparable duration: middle-late Eocene (40 Ma to $33.9 \mathrm{Ma}$ 
$\sim 6 \mathrm{Ma}$ ), early Oligocene (33.9 Ma to $27.82 \mathrm{Ma} \sim 6 \mathrm{Ma}$ ), late Oligocene (27.82 Ma to $23.03 \mathrm{Ma} \sim 5 \mathrm{Ma}$ ), and early Miocene $(23.03 \mathrm{Ma}$ to $16 \mathrm{Ma} \sim 7 \mathrm{Ma})$. Phylogenetically estimated diversity metrics (i.e. taxic count + ghost lineages) were then plotted against time.

\section{Disparity analysis}

Disparity refers to morphological diversity or variety (Gould 1991; Foote 1993a, 1997). It can be described by diverse parameters or indices, most of them focused on quantification of pairwise distances of studied taxa (Foote 1997; Ciampaglio et al. 2001), and visualized by plotting them in a morphospace reflecting distance information (Wills 2001). Disparity indices are used to evaluate morphological dissimilarity between taxa within groups, and to detect and measure patterns of morphological change over geological time.

To quantify the morphological diversity among paucituberculatans we followed a general protocol described by Lloyd (2016) and implemented by the R package Claddis (Lloyd 2016). Both $\mathrm{R}$ package and a brief tutorial are available in GitHub (https://github.com/graemetlloyd/Claddis). Discrete morphological characters, derived from a cladistic data-set (see Phylogenetic Analysis), were used to construct a matrix of pairwise inter-taxon distances. Hypothetical ancestors were included in the matrix in order to phylogenetically correct measures of disparity, as proposed by Brusatte et al. (2011). Ancestral morphologies as implied by phylogeny, were then reconstructed using both accelerated transformation (ACCTRAN) and delayed transformation (DELTRAN) optimization methods. Since no differences arose from these, we used ACCTRAN optimization results only. The distance matrix was based on Generalized Euclidean Distance metric (GED; Wills 1998), as our preferred distance measurement (see SM4.7). The distance matrix was calculated using the command MorphDistMatrix of the Claddis package. Given that GED can cope with missing entries leading to noncomparable pairwise characters (Lloyd 2016), we test for the presence of non-comparable pairs (which would introduce bias) by comparing the GED data matrix with the matrix of comparable characters looking for non-coincidences. We did not find any non-comparable taxon-taxon pairs. Taxa and nodes showing redundant information were pruned before calculation of the metrics. In addition, in order to compare GED results with other available distance metrics, we determinated the pairwise distance between taxa and reconstructed ancestors with three other metrics: Raw Euclidean Distance (RED), Gowers's Coefficient (GC), and Maximum Observable Rescaled Distance (MORD) (see SM4.7). Since GED matrix is suitable for Principal Coordinates Analysis (PCo - Multi Dimensional Scaling; Wills 1998), this ordination method was used for morphospace construction, using the command cmdscale from the R package stats (R Core Team 2017). To obtain triangular distance matrices for calculations, we used the commands upperTriangle (R package gdata; Warnes et al. 2015) and as.dist ( $\mathrm{R}$ core package stats).

Among the diverse disparity measures that have been proposed (Foote 1997; Ciampaglio et al. 2001) we chose as our pre-ordination metric the Weighted Mean Pairwise
Distance (WMPD; distances weighted by the ratio of comparable characters), and two metrics that require ordination and are therefore computed on PCo scores: Sum of Variances and Sum of Ranges (SV and SR, respectively; see Lloyd 2016). WMPD has proved to be robust to sample size and for data sets with common missing entries (Foote 1994; Ciampaglio et al. 2001; Lloyd 2016), therefore it considered appropriate for the present analysis. Post-ordination metrics such as product of variances and ranges have been used in many studies of disparity in both invertebrates and vertebrates (e.g. Wills et al. 1994; Wills 1998; Brusatte et al. 2008b; Benson et al. 2012), but they can over-amplify differences within groups, and therefore we preferred to use SV and SR as considering them more conservative. Variance-based measures express the dispersion of points in the morphospace, and therefore they are more appropriate where the concern is with the average dissimilarity between forms (Wills et al. 1994; Wills 2001). Range-based measures, on the other hand, express morphospace size (i.e., total extent of morphological variability, Wills et al. 1994); being insensitive to the distribution of points, they are free from biases caused by taxonomic practice (differential lumping or splitting of taxa). For SV and SR, only those PCo eigenvectors accounting for most of variability were used (based on cumulative variance histograms or scree-plots - see SM4.4), in order to avoid downsizing effect introduced by lower-than 0.5 variances (Lloyd 2016). Interquartile intervals were calculated by an ad hoc programmed $\mathrm{R}$ function for jack-knifing on the original taxacharacter matrices, and are provided in SM4.3 (R script for jack-knife is included in SM4.6).

Disparity metrics were calculated for the following systematic groups: Paucituberculata as a whole, Caenolestidae, Pichipilidae and NPP (SM4). As for diversity, disparity measurements were estimated for four time bins: middle-late Eocene, early Oligocene, late Oligocene and, early Miocene (SM4).

In order to assess the statistical significance of differences between successive time bins and since GED and PCo scores had proven to show non-normal distribution (SM4.5), non-parametric (Mann-Whitney U test, Kruskal-Wallis rank sum tests and Wilkoxon pairwise tests) tests were used both on raw GED and PCo scores on one hand, and on jack-knifed resampled distributions of WMPD, SV and SR (Table 2) on the other. R commands kruskal.test and wilcox.test were used (core package stats).

\section{Body size evolution}

\section{Body mass estimation of terminal taxa}

Body mass was estimated from the area measurement (maximal length $\mathrm{x}$ width) of the lower second molar ( $\mathrm{m} 2)$ and maximal length of the third lower molar (m3), using linear regression equations derived from living marsupials and presented by Dumont et al. (2000) and Gordon (2003), respectively. We found that Gordon's equation provided, among other available equations (e.g. Dumont et al. 2000; Myers 2001), the most accurate body mass estimation for living caenolestids (SM5, Table 1) and thus we assumed this would be the best predictive equations to estimate body mass in extinct caenolestids, as well as other taxa with a generalized molar pattern, such as basal paucituberculatans and outgroups. On the other hand, Dumont 
Table 1. Disparity and diversity metrics.

\begin{tabular}{|c|c|c|c|}
\hline \multicolumn{4}{|c|}{ Disparity values compared by groups } \\
\hline & Weighted Mean & Sum of Variances & Sum of Ranges \\
\hline Caenolestidae & 3.475 & 6.617 & 18.757 \\
\hline Pichipilidae & 3.575 & 7.136 & 15.495 \\
\hline \multicolumn{4}{|l|}{ Disparity of NPP } \\
\hline Time bin & Weighted Mean & Sum of Variances & Sum of Ranges \\
\hline late Oligocene & 4.1295 & 8.1169 & 17.7205 \\
\hline early Miocene & 3.7266 & 6.4750 & 16.4894 \\
\hline \multicolumn{4}{|l|}{ Taxonomic diversity of NPP } \\
\hline Time bin & taxic estimate & ghost lineages & phylogenetic estimate \\
\hline middle-late Eocene & 3 & 11 & 14 \\
\hline Time bin & taxic estimate & ghost lineages & phylogenetic estimate \\
\hline early Oligocene & & $A(4) ; P(9)$ & A (4); P (9) \\
\hline late Oligocene & $A(1) ; P(3)$ & A (9); P (13) & A (10); P (16) \\
\hline early Miocene & A (6); P (13) & $A(2) ; P(8)$ & $\mathrm{A}(8) ; \mathrm{P}(21)$ \\
\hline
\end{tabular}

Table 2. Statistical test for significant differences in disparity metrics between time-bins.

\begin{tabular}{|c|c|c|c|}
\hline \multicolumn{4}{|l|}{ tests on GEDs } \\
\hline \multicolumn{4}{|c|}{ Mann-Whitney U test of distances between succesive time bins } \\
\hline & $\mathrm{U}$ & $p$-value & estimate \\
\hline Eocene vs early Oligocene & 380 & 0.9735 & 0.0043 \\
\hline early vs late Oligocene & 603 & 0.0016 & -0.7480 \\
\hline late Oligocene vs Miocene & 3828 & 0.0896 & 0.3094 \\
\hline \multicolumn{4}{|c|}{ Kruskal-Wallis test of distances between succesive time bins } \\
\hline & chi-squared & $\mathrm{df}$ & $p$-value \\
\hline Eocene vs early Oligocene & 0.001 & 1 & 0.9736 \\
\hline early vs late Oligocene & 9.8676 & 1 & 0.0016 \\
\hline late Oligocene vs Miocene & 2.8801 & 1 & 0.0896 \\
\hline \multicolumn{4}{|c|}{ Wilcoxon pairwise rank sum test of distances between time bins } \\
\hline & Eocene & early Oligocene & late Oligocen \\
\hline early Oligocene & 0.9801 & - & - \\
\hline late Oligocene & 0.0547 & 0.0102 & - \\
\hline Miocene & 0.2699 & 0.1695 & 0.2699 \\
\hline \multicolumn{4}{|c|}{ Wilcoxon pairwise rank sum test of jack-kniffed WM between time bins } \\
\hline & Eocene & early Oligocene & late Oligocen€ \\
\hline early Oligocene & 0.5360 & - & - \\
\hline late Oligocene & 0.0001 & 0.0000 & - \\
\hline Miocene & 0.0000 & 0.0000 & 0.0000 \\
\hline \multicolumn{4}{|l|}{ tests on PCO scores } \\
\hline \multicolumn{4}{|c|}{ Kruskal-Wallis test of $P C O$ scores between succesive time bins } \\
\hline & chi-squared & df & $\mathrm{p}$-value \\
\hline Eocene vs early Oligocene & 0.47 & 1 & 0.4901 \\
\hline early vs late Oligocene & 1.44 & 1 & 0.2297 \\
\hline late Oligocene vs Miocene & 0.02 & 1 & 0.8778 \\
\hline \multicolumn{4}{|c|}{ Wilcoxon pairwise rank sum test of jack-kniffed SV between time bins } \\
\hline & Eocene & early Oligocene & late Oligocen \\
\hline Early Oligocene & 0,9789 & - & - \\
\hline Late Oligocene & 0,0002 & 0,0000 & - \\
\hline Miocene & 0,9789 & 0.0239 & 0,0000 \\
\hline \multicolumn{4}{|c|}{ Wilcoxon pairwise rank sum test of jack-kniffed SR between time bins } \\
\hline & Eocene & early Oligocene & late Oligocene \\
\hline Early Oligocene & 0.0907 & - & - \\
\hline Late Oligocene & 0.0001 & 0,0000 & - \\
\hline Miocene & 0,0001 & 0,0000 & 0.0002 \\
\hline
\end{tabular}


et al. (2000) equation was applied for the remaining, more derived species, as it was done in previous studies (Abello et al. 2010; Rincón et al. 2015; Engelman et al. 2016). In only two basal paucituberculatans, with no preserved $\mathrm{m} 2$ or $\mathrm{m} 3$ (Bardalestes hunco and Bardalestes sp.), the equation of Gordon (2003) generated from M2 maximum length was used. For each regression equation, smearing estimates, a correction factor to deal with the logarithmic detransformation bias (Smith 1993), was calculated and multiplied for each estimated value of mean body mass (SM5, Table 2). Body masses of extant caenolestids were taken from the published literature (Kirsch and Waller 1979; Albuja and Patterson 1996; Patterson 2007).

\section{Mapping of body mass}

In order to analyze the evolution of body mass we chose to map this continuous character on paucituberculatan phylogeny by linear parsimony (Swofford and Maddison 1987) using TNT 1.5beta (Goloboff et al. 2003). Then, and following Giannini et al. (2012) and Amador and Giannini (2016), the resulting pattern of change of body masses was evaluated by a node-by-node descriptive approach in the framework proposed by Gould and MacFadden (2004). In this way, four kinds of body size changes could be identified: autapomorphic gigantism and nanism, and phyletic gigantism and nanism. Autapomorphic changes are recognized as those occurring in a single branch of a clade, while phyletic ones are those occurring in nested clades (see Gould and MacFadden 2004). The persistence of a phyletic pattern was assessed, as proposed by Amador and Giannini (2016), considering the order of phyletic change as the number of consecutive branches composing the phyletic pattern. In the context of body size evolution of paucituberculatans, we considered a species to be a giant if its body mass resulted more than $200 \%$ increase with respect to the reconstructed ancestor, and a nanism if its body mass represented more than two-fold size decrease with respect to the reconstructed ancestor.

\section{Phylogenetical autocorrelation of body size}

To test for phylogenetical autocorrelation of body mass, we performed two different analyses, one for Paucituberculata as a whole and the other for the NPP only. Given that bodymass estimates were not available for all taxa considered, several of them had to be pruned from the matrices in order to perform these analyses (Riolestes capricornicus, Fieratherium sorex and Pliolestes venetus). Most available tests for phylogenetical autocorrelation require fully dichotomous trees and/or branch lengths (see Paradis 2006; Münkemüller et al. 2012). However, the phylogenetic hypothesis considered in this work resulting in a cladogram including several polytomies. Tools for solving polytomies by random splitting of daughter branches can be considered as rendering artificial, spurious phylogenetical hypotheses. In addition, we consider that estimating divergence times from fossil record imply ad-hoc statistic and evolutionary assumptions (for instance, inference of 0-length internal branches and/or estimation of branching-extinction rates; see Ollier et al. 2006; and Paradis 2006; Münkemüller et al. 2012; for a review of methods). Therefore, in this study we preferred to use tests not relying on branch lengths but only on cladogram topology, and also those allowing polytomies. Such analytical tools are the Orthonormal Decomposition by Ollier et al. (2006) and the Abouheif's C test (Abouheif 1999).

All tests were performed in R, using different tools from the ape (Paradis et al. 2004), ade4 (Dray and Dufour 2007), adephylo (Jombart et al. 2010), geiger (Harmon et al. 2008), and phylosignal (Keck et al. 2016) packages.

\section{Orthonormal decomposition}

The Orthonormal Decomposition test (in the ade4 package) operates by building a matrix of orthobases (i.e. orthonormal vectors describing the topology of the tree) and then analyzing the dependence of the variance of the studied variable (log-transformed body size) on that set of vectors by four non-parametric statistics. Monte Carlo permutations of the vector matrix against the studied variable allow construction of a null-model of nocorrelation and confidence intervals (at alpha 0.05) for the statistics. The R2Max (maximal R2) peaks when a significant portion of variance dependence is detected at a single node (otherwise dependence is dispersed along several nodes). The Dmax (maximal deviation), corresponding to the Kolmogorov-Smirnov statistic, tests if the variable studied could be considered a random sample from a uniform distribution. The SkR2k (sum of k-nth R2) describes the trend of the variance distribution to be skewed toward the tree's tips or root. Finally, the SCE (sum of cumulative errors) depicts the averaged variation.

\section{Abouheif's c-mean}

the Abouheif's C index can be viewed as a special case of the spatial correlation Moran's I index. It was performed to test the correlation between the studied variable (log-transformed body size) and a matrix of phylogenetic proximities with nonnull diagonal (see Pavoine et al. 2008) describing the cladogram topology. We calculated the proximity matrix using the 'oriAbouheif method of the command proxTips (adephylo $\mathrm{R}$ package), as discussed in Pavoine et al. (2008), and then we used this matrix for the command Moran.I of the ape $\mathrm{R}$ package. The null-hypothesis is the absence of correlation (C-mean equal 0 ) and its significance is tested against a distribution built on permutations (see SM5).

\section{Coupling between disparity and body mass}

In order to search for putative correlation between morphological disparity and body size variability, several statistical tests were performed. Pearson correlation tests between both maximum GED and log-transformed body mass, and between first PCo scores and log body mass, at a 0.05 significance level were calculated using the cor.test command of the stats $\mathrm{R}$ core package. In addition, linear regression of both maximum GED and first PCo scores on log-transformed body mass were calculated using the $\operatorname{lm}$ commands of the stats $\mathrm{R}$ core package.

\section{Results}

\section{Paucituberculatan phylogeny}

The strict consensus trees (SCT) and branch support values resulting from the analyses of reduced and total matrixes using 


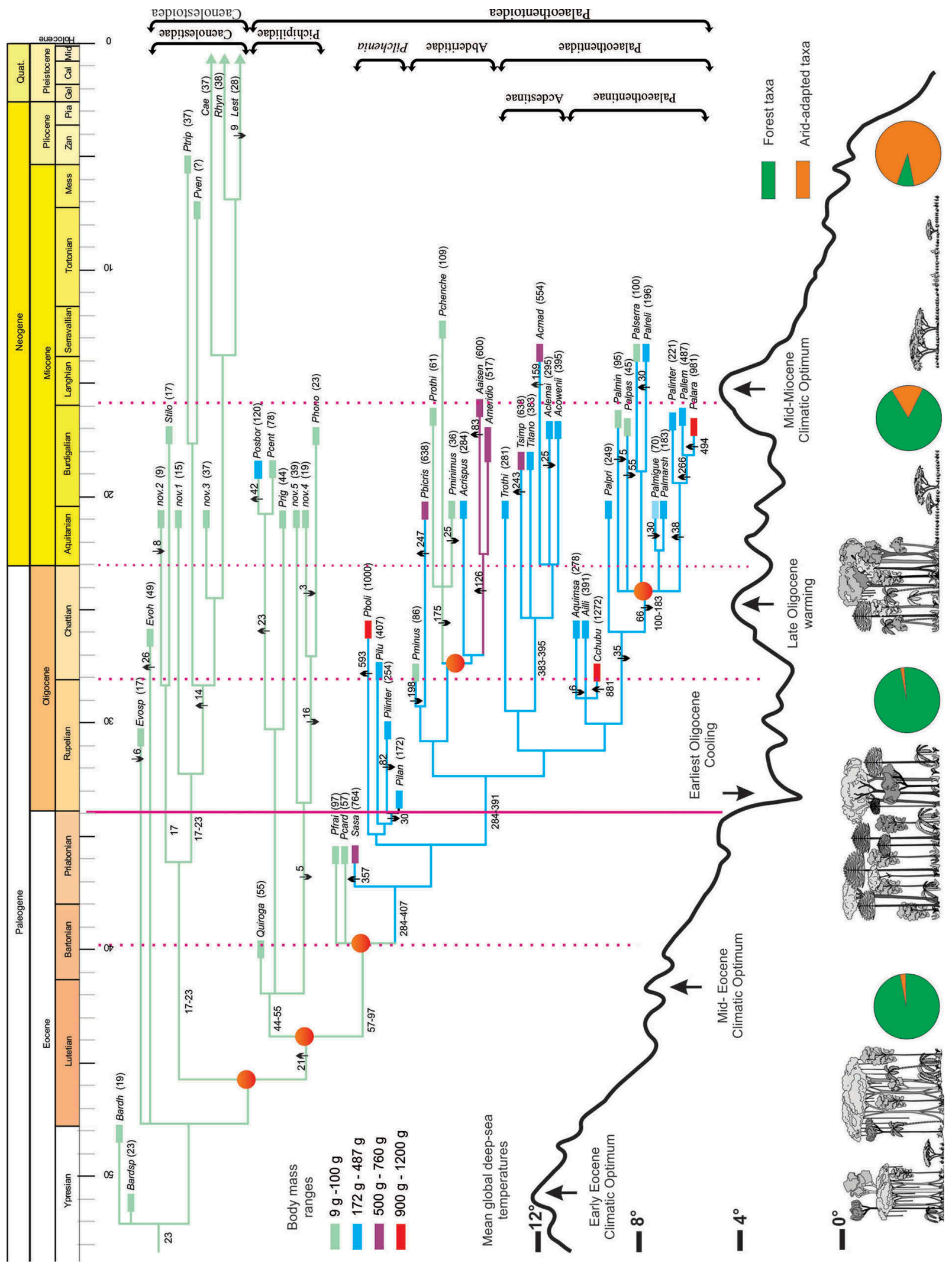

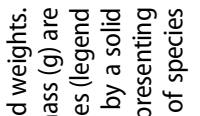

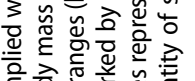

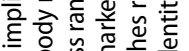

훈 운

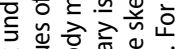

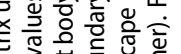

형

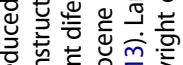

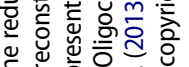

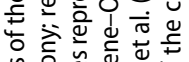

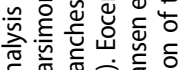

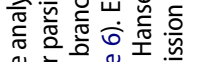

๘

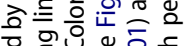

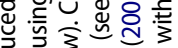

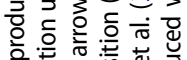

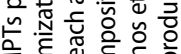

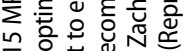

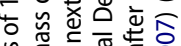

ज ₹

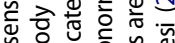

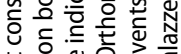

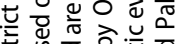

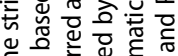

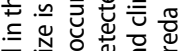

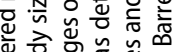

웅 중 方

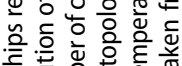

등 है ह 웜

品 空芯

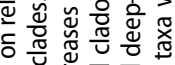

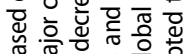

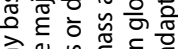

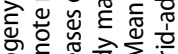

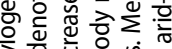

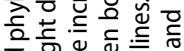

원

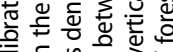

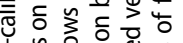

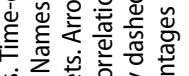

柁

등

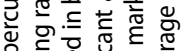

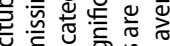

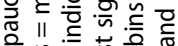

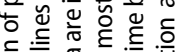

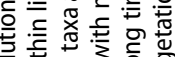

के

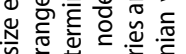

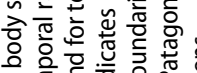

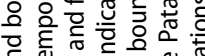

范

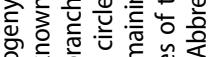

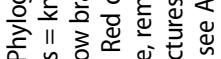

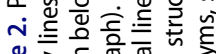
Whin 
equal weighting and implied weighting are given in the SM2. Analysis of the reduced matrix yielded consensus trees with a higher number of nodes than those of the total matrix, providing more information about the evolution of paucituberculatans. The topology of the SCT resulting from the analysis of the reduced matrix under implied weighting differs only from that obtained using equal weighting in that the Pilchenia clade was fully resolved. In the following, the SCT topology recovered in this latter analysis (Figure 2) will be discussed in relation to recent hypotheses of paucituberculatan phylogeny.

As a result of this work, and in agreement with previous hypotheses (Abello 2013; Rincón et al. 2015; Engelman et al. 2016) Paucituberculata encompasses two main groupings, Caenolestoidea and Palaeothentoidea, and several basal taxa (Figure 2): Fieratherium sorex, Bardalestes spp. and Evolestes spp. However, and in contrast with earlier analyses (Abello 2013; Engelman et al. 2016), Riolestes capricornicus was excluded from Paucituberculata. On the other hand, Evolestes hadrommatos and Evolestes sp. were recovered, resembling the phylogeny of Engelman et al. (2016), as the paucituberculatan taxa most closely related to the Caenolestoidea +Palaeothentoidea clade.

The general topology of the Caenolestoidea clade is similar to that obtained by Abello (2013) and Engelman et al. (2016), and only differs in recovering Stilotherium as the sister-group to remaining caenolestoids. The Palaeothentoidea comprises two main clades: Pichipilidae and NPP. The Pichipilidae topology was improved by the recovering of the Pichipilus clade and the monophyly of Phonocdromus gracilis, sp. nov 5 and sp. nov 4 . Similarly to earlier mentioned studies, within the NPP clade Perulestes spp. are sister to the remaining taxa, and Sasawatsu is the sister-group to a clade that clusters Pilchenia spp., abderitids and palaeothentids. Among the NPP, Abderitidae was recovered with the same topology as that resulting in previous analyses: Parabderites (Abderites + Pitheculites). For the remaining NPP, the greatest differences with previous hypotheses (see, e.g. Rincón et al. 2015) are focused on the phylogenetic relationships among palaeothentines and Pilchenia spp. Pilchenia species were recovered as a clade, sister to Palaeothentidae + Abderitidae, as in Abello (2013) and Engelman et al. (2016, analysis under equal weighting), and not as a part of Palaeothentidae as in Engelman et al. (2016, analysis under implied weighting) and Rincón et al. (2015). Our Palaeothentidae topology largely agrees with that of Engelman et al. (2016, analysis under equal weighting); it includes two main groupings, Acdestinae and Palaeothentinae, and within the latter Palaepanorthus primus is the sister-group to Palaeothentes. In contrast, our results recovered a Antawallalestes -Carlothentes clade, which was positioned as sister-group to the Palaepanorthus-Palaeothentes clade.

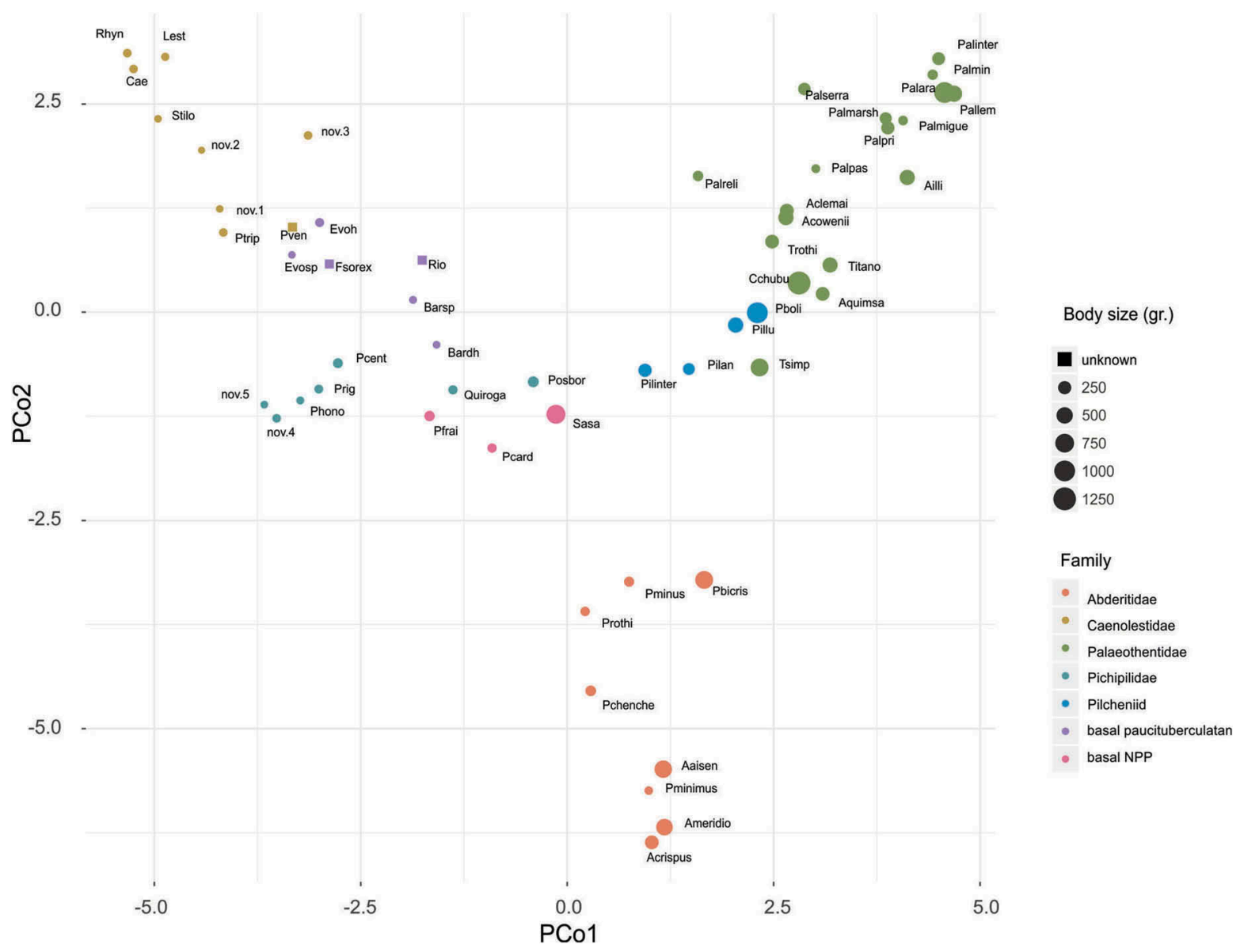

Figure 3. Morphospace occupation for paucituberculatans based on the first two principal coordinate axes. Major paucituberculatan groupings (Caenolestidae, Pichipilidae, Pilchenia, Abderitidae, Palaeothentidae) and basal taxa (basal paucituberculatans and basal NPP) are differently colored (legend on graph). Size of circles that represent each species indicates the reconstructed body mass (legend on graph). For identity of species acronyms, see Abbreviations. 

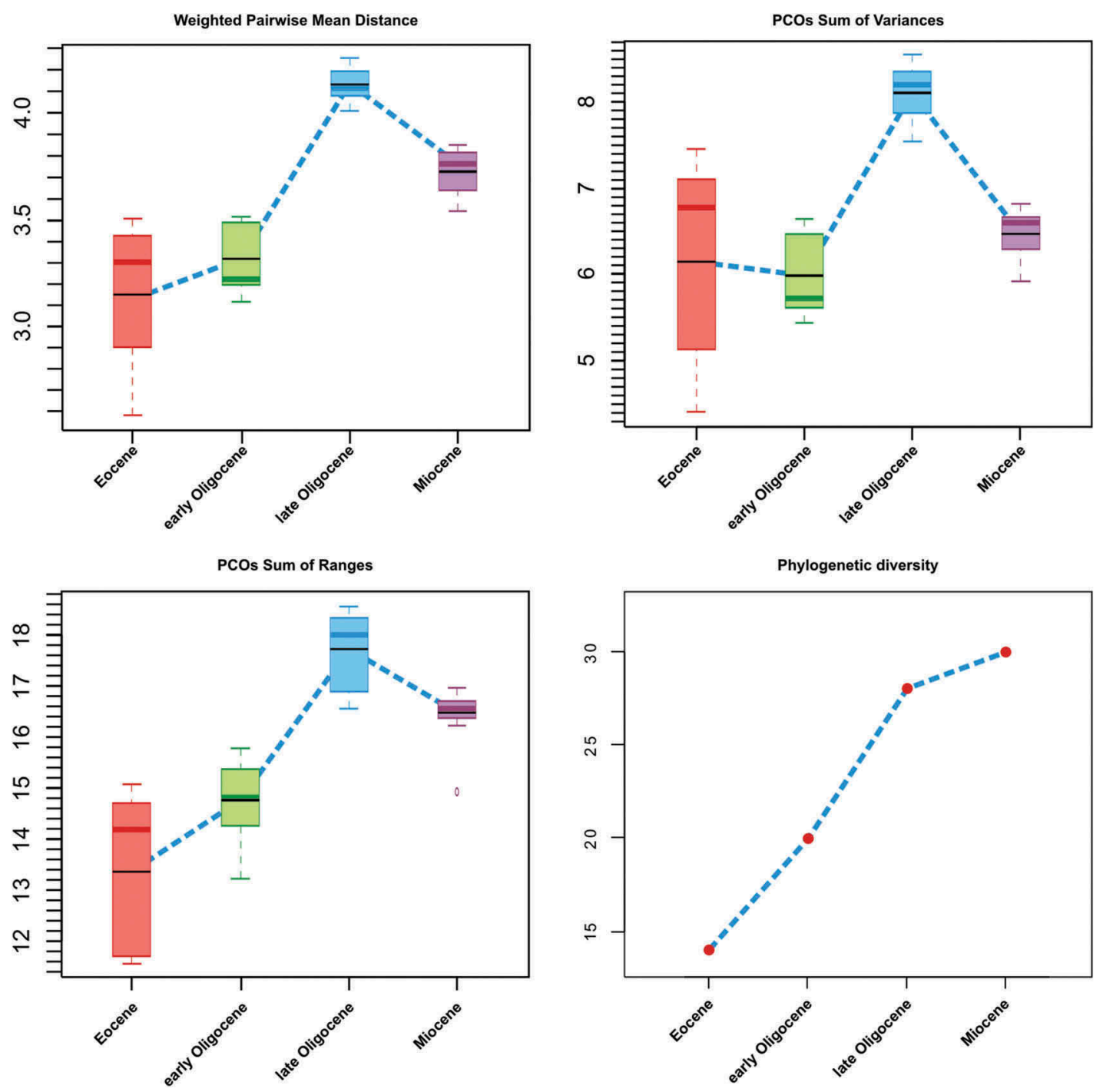

Figure 4. Phylogenetically corrected disparity and diversity metrics of non-Pihipilidae palaeothentoids through time. Interquartile intervals built on jack-knifed resampled distributions.

\section{Diversity analysis}

With thirty-five recognized species, the NPP is the taxonomically richest paucituberculatan clade (SM3). Otherwise, caenolestids group thirteen species, seven of which are living (Ojala-Barbour et al. 2013), and pichipilids include eight extinct species. The fossil record of both caenolestids and pichipilids is best in the Miocene, therefore long ghost lineages have emerged from their inferred origins in the middle Eocene (Figure 2). In contrast, the NPP are relatively well recorded since the late Eocene and showed an increase of phylogenetically corrected diversity over time. Their diversity strongly increased from the early to late Oligocene, and later on, during the early Miocene, showed the highest value. Comparing the NPP clades, palaeothentids were more diverse than abderitids in all time bins, and both groups had their highest diversity values in different times: abderitids in the late Oligocene, and palaeothentids in the early Miocene (Table 1). From the counting of the recorded NPP species and ghost lineages in each time-bin (Table 1), it can be seen that taxic diversity estimates for the Eocene and Oligocene resulted in a large underestimate of diversity values with respect to those calculated taking into account the phylogenetic information.

\section{Disparity analysis}

Non-Pichipilidae palaeothentoids (NPP) were significantly more disparate than caenolestids and pichipilids (Tables 1 and 2; Figure 3). Regarding disparity differences of the NPP over geological time, Euclidean distances show a marked disparity increase from the early Oligocene to the late Oligocene, and a drop from the late Oligocene to the early Miocene (Figure 4). Statistical tests performed on Euclidean distances and jack-knifed WMs (see Table 2) showed no significant differences between Eocene and early Oligocene data, and some found no significant differences between late Oligocene and Miocene data either. In contrast, significant differences between early and late Oligocene data were found, indicating that pre-ordination disparity has changed through Oligocene. In addition, 


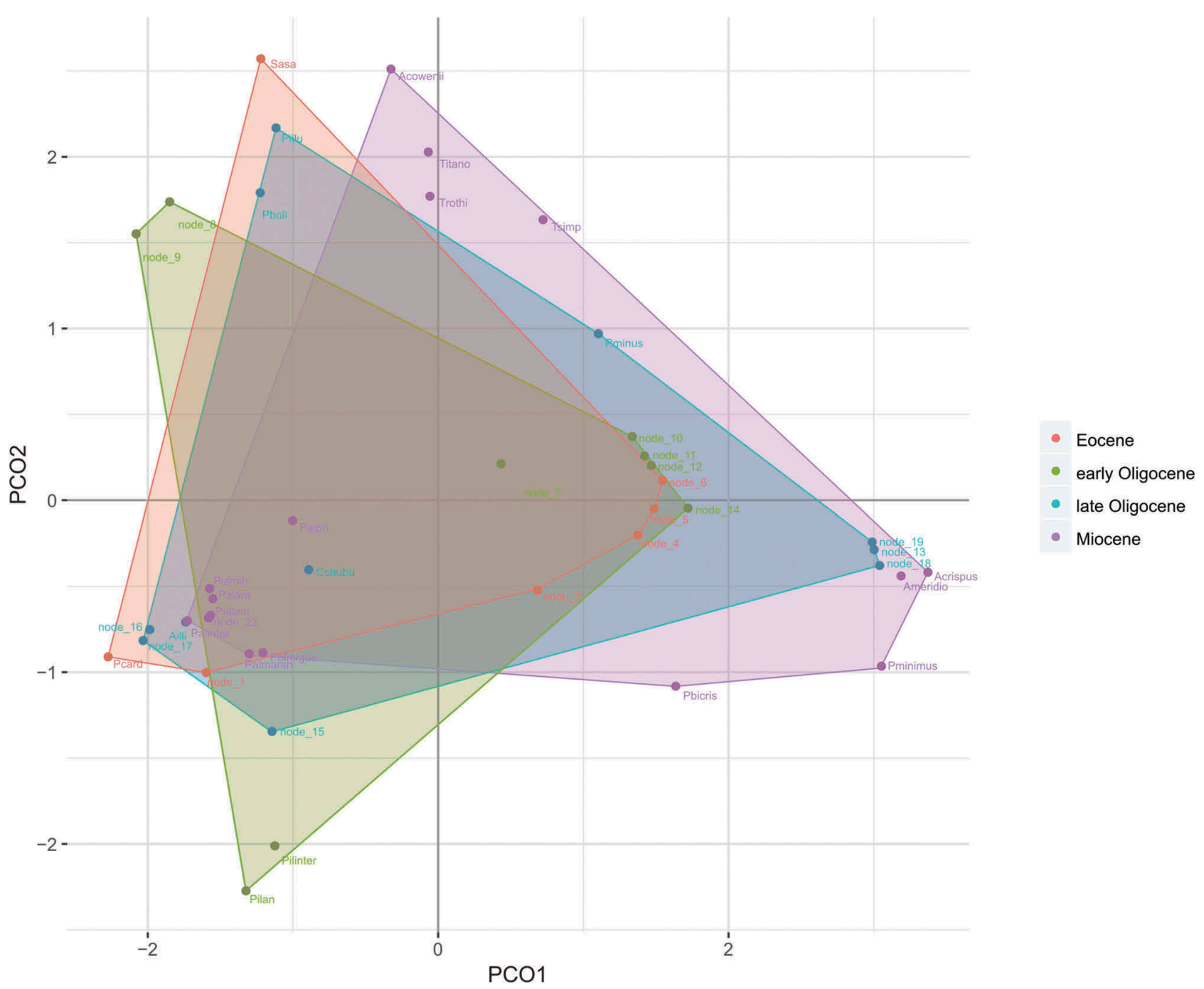

Figure 5. Morphospace occupation by non-Pichipilidae palaeothentoids over time. Plots are based on the first two axes from the PCo. Minimal morphospace occupation by taxa and reconstructed ancestors of each time bin are indicated by differently colored convex hulls (legend on graph). For identity of species acronym, see Abbreviations.

some tests found significant differences between jackknifed late Oligocene and Miocene WMs (Table 2). Results of pre-ordination metrics based on RED and GC are mostly coincident with those found with GED. In contrast to GED, RED and GC recovered a significant increase between Eocene and early Oligocene, but a similar disparity trajectory as GED in latter time-bins: a significant disparity increase between early Oligocene and late Oligocene, and a decrease between late Oligocene and early Miocene (see SM4.7).

Analyzing post-ordination distances based on GED, SV behaved similar to SR, suggesting an increase of disparity from early to late Oligocene. This can be recognized as an expansion and dispersion of the occupied morphospace (see Figure 5). On the other hand, SR (similarly to WMPD) shows a small increase from the late Eocene to the early Oligocene but, in contrast to WMPD and SV, there is an increase from the late Oligocene to the early Miocene. However, statistical tests performed on PCo scores did not find significant differences between these successive time-bins (Table 2). On the other hand, tests performed on distributions of SVs and SRs generated by jack-knifing of the matrices rendered significant differences between both early and late Oligocene and between late Oligocene and Miocene (Table 2).

\section{Evolution of body size}

Estimated body masses of paucituberculatans range from $9 \mathrm{~g}$ for the caenolestid sp. nov. 2, to $1272 \mathrm{~g}$ in Carlothentes boliviensis (SM5, Table 2). Caenolestids and pichipilids includes small species $($ mean $=40 \mathrm{~g}$ ), except for the medium-sized pichipilid P. osborni of $120 \mathrm{~g}$. During their evolutionary history, caenolestids and pichipilids remained smallsized (Figure 2). However, certain phyletic changes can be seen, particularly among pichipilids, in which a succesive increase in size is seen in the Pichipilus clade, while a decrease occurs in the clade that groups Phonocdromus gracilis, sp. nov 5 and sp. nov 4 . In contrast to the mentioned paucituberculatans, the NPP have a significatively broader range of body masses (SM5, Figure 1). Among the smallest species are the abderitids Parabderites minusculus and Pitheculites spp. (36 g 


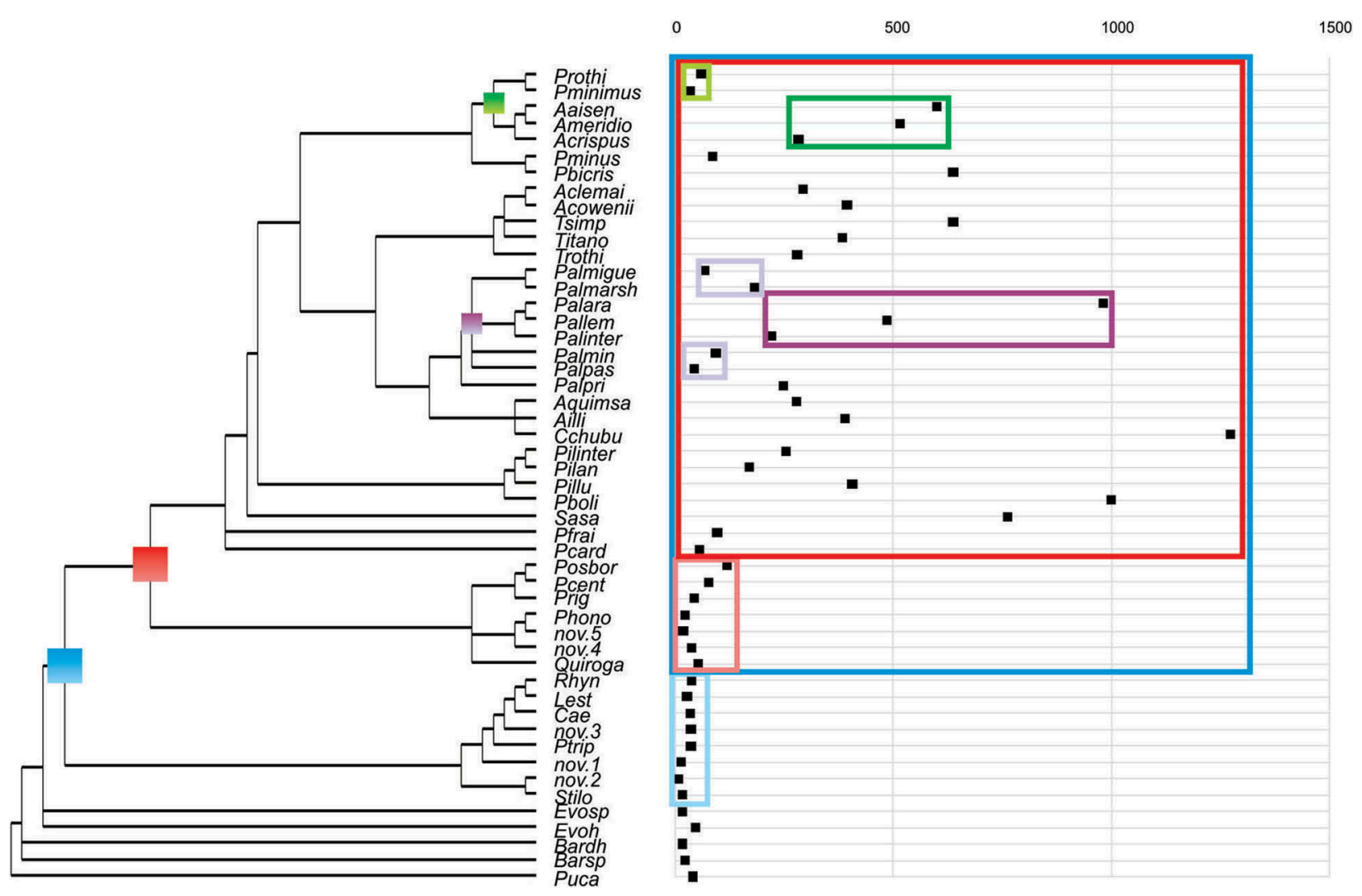

Figure 6. Paucituberculatan reconstructed body masses plotted on the cladogram (using the function dotchart.phylog of the R package ade4) highlighting nodes with most significant autocorrelation signal as detected by orthonormal decomposition (see SM5). En each highlighted node, distribution of body masses in each of its descendant clades is depicted in different shades of color to enhance visualizations of evolutionary patterns of size variability.

to $109 \mathrm{~g}$ ), and the palaeothentids Palaeothentes pascuali and $P$. minutus (45g and $95 \mathrm{~g}$ respectively). The largest NPP include Pilchenia boliviensis (1000g), C. chubutensis and the palaeothentid Palaeothentes aratae $(900 \mathrm{~g})$. In the earliest cladogenesis of the NPP, there is a sharp change of body masses from $57 \mathrm{~g}-97 \mathrm{~g}$ to $284 \mathrm{~g}-407 \mathrm{~g}$, at the node that clusters Sasawatsu, Pilchenia, abderitids and palaeothentids. With a $292 \%$ increase, this represent one of the largest changes in paucituberculatan body size evolution. Afterwards, from medium-sized ancestors $(284 \mathrm{~g}-407 \mathrm{~g})$, all the NPP major clades underwent increases and/or decreases in body masses. The Pilchenia clade includes one large species, $P$. boliviensis, and a group of smaller species, ranging from $407 \mathrm{~g}$ in $P$. lucina to $172 \mathrm{~g}$ in $P$. antiqua, which exhibits a trend of size decrease. Among abderitids, a phyletic trend of increased body mass is present in the Abderites clade, while its sister-group Pitheculites clusters some of the smaller NPP. The evolutionary change leading to Pithecultites involved a net decrease of $175 \mathrm{~g}(260 \%$ decrease), and thus represents the second largest decrease among paucituberculatans after that of the autapomorphic nanism represented by the abdertitid $P$. minusculus ( $-198 \mathrm{~g}$ or $330 \%$ decrease). Similar to abderitids, palaeothentids include a diverse size range of paucituberculatans. Acdestines do not exhibit trends in body mass changes, and include only medium- to large-sized species. Among the largest species were Acdestis maddeni (554g) and Titanothentes simpsoni (638g). On the other hand, palaeothentines include an autapomorphic giant, C. chubutensis $(+881 \mathrm{~g}$ or $225 \%$ increase) and several of the smaller
NPP, which are grouped in the Palaeothentes clade (e.g. $P$. pascuali). A trend towards body size decrease is present in the lineage leading to Palaeothentes. Within Palaeothentes, a successive size increase along three branches is seen in the $P$. intermedius ( $P$. aratae- $P$. lemoinei) clade, thus representing a third-order case of phyletic giantism. In this trend, $P$. aratae achieves its larger size accumulating $798 \mathrm{~g}$ from the Palaeothentes node, which represents a total increase of 536\%.

Significant phylogenetic autocorrelation was detected by the Orthonormal Decomposition and Abouheif C methods, implying that body size variability was significantly linked to phylogeny, i.e. that closely related species have a greater probability of having similar body size values. Orthonormal Decomposition detected significant autocorrelation in several nodes illustrated in Figure 6. Abouheif $\mathrm{C}$ was significantly different from the null-model in both Paucituberculata and the NPP clades, supporting those results (SM5). In addition, Orthonormal Decomposition allows a finer exploration of autocorrelation. For each significant orthobase describing a given node with high autocorrelation, the same pattern could be recognized: one descendant clade showing high variability in body mass, while the other descendant clade shows a constrained diversity in body mass, therefore suggesting that members of the latter clade share an inherited pattern of body size (Figure 6). Concerning non-parametric statistics tested on orthobases, all four of them were significantly different from the uniform null-model for the entire Paucituberculata tree (see SM5), indicating that strong autocorrelation was focused on a few basal nodes, influencing derived branches. 
When applied exclusively to the NPP tree, R2Max was the only statistic that was not significantly different from the nullmodel, indicating that the autocorrelation was not concentrated on a few basal nodes but spread over several more derived ones (see Ollier et al. 2006). In addition, graphical tools accompanying $\mathrm{R}$ implementation of Orthonormal Decomposition allow exploration of those nodes with stronger signal, which are depicted in Figure 6 and in SM5 (summarising information of most significant nodes over the orthobases matrix). Most significant nodes are those joining caenolestids and the remaining paucituberculatans on one hand, and those joining pichipilids and NPP on the other. Following these most significant nodes, there are those joining species within Palaeothentes; and joining the Abderites and Pitheculites clades.

Correlation between disparity (depicted as GEDs and PCo scores from the pruned matrix) and body size as tested herein did not find a significant relationship. Therefore, we may conclude that there is no direct link between morphological disparity and body size. Indeed, evolutionary changes in body size as detected by means of cladogram mapping and autocorrelation statistic show no coupling with greater changes in disparity as suggested by our analyses. Instead, greater changes in disparity occur between the early and late Oligocene, while significant evolutionary changes in body size appear to occur mainly during the middle Eocene and late Oligocene-Miocene (see Figure 2).

\section{Discussion}

\section{Climates and environments in south america during the eocene and the origin of the NPP}

During the Eocene, global temperatures were high and greenhouse conditions persisted up to the end of this period (Zachos et al. 2001, 2008; Hansen et al. 2013). No major Atlantic transgressions occurred, except for that which partially flooded southern Patagonia during the late middle Eocene (Malumian and Nañez 2011), and the most intense uplift pulses of the Andes had not yet begun (Hoorn et al. 2010; Ramos and Ghiglione 2008). Paleobotanical and palynological evidence indicate that vegetation was of tropical and subtropical type, widespread in South America, reaching middle and high latitudes with a high floral richness (Wilf et al. 2005; Jaramillo et al. 2006). During the early Eocene there was a predominance of the floristic elements indicating hot and humid climates in southern South America. The climatic reconstructions derived from this flora indicate subtropical temperatures and bi-seasonal precipitations (Villagrán and Hinojosa 2005; Barreda and Palazzesi 2007), although other studies suggest somewhat lower precipitation for the flora of central-western Patagonia (Wilf et al. 2013). From the middle Eocene to the early Oligocene, an expansion of the Nothofagus forests indicates a progressive replacement of the subtropical flora by a more temperate one (Barreda and Palazzesi 2010). Climatic seasonality is recorded (Barreda and Palazzesi 2010) and there are a few indicators of xeric environments (Villagrán and Hinojosa 2005; Barreda and Palazzesi 2007). Notwithstanding, during the middle Eocene phytolithic associations show the predominance of forest environments and the first evidence of mega-thermic grasses in central Patagonia, although these grasses had a low abundance (Zucol et al. 2010; Strömberg et al. 2013). These paleoenvironmental inferences derived from the flora coincide with those derived from mammalian faunas. During the early and middle Eocene, mammal communities were dominated by browsing types, with a low diversity of mixed feeders and 'grazers' (i.e., mammals with hypsodont/hypselodont molar morphologies that may have fed on grasses and/or vegetation with exogenous grit). The browsers, together with the insectivore and the omnivore-insectivore types, allow us to infer the existence of subtropical forest environments, developed under hot and humid climates (OrtizJaureguizar and Cladera 2006). Finally, during the late Eocene mammalian communities continue to be dominated by browsers, but the diversity of mixed feeders and 'grazers' increased. This rise in diversity of these two groups suggests a similar increase of open environments (Ortiz-Jaureguizar and Cladera 2006). The NPP arose in this paleoenvironmental context, approximately 43-45 Ma ago (middle Eocene, Figure 2). At the time, they expanded their taxonomic diversity and disparity, as expected in an initial radiation (Foote 1993b). Mammal assemblages where early NPP have been found, show that they coexisted with other small-sized mammals such as basal 'ameridelphians' (see Goin et al. 2016) and polidolopimorphian metatherians, and the first caviomorph rodents and primates registered in South America (Frailey and Campbell 2004; Goin and Candela 2004; Bond et al. 2015; Antoine et al. 2016). The first NPP were small-sized, as were members of their sistergroup Pichipilidae and the most basal caenolestids, but early in their history they became larger. Approximately between 38 and $39 \mathrm{Ma}$, a threefold increase in body size occurred in the evolution of the NPP (see Figure 2). This change is concurrent with a functional and taxonomic turnover in metatherian assemblages identified at least in southern South America (Goin et al. 2016). This turnover has been related to an abrupt fall in precipitation and the establishment of relatively warm but more arid conditions from the early late Eocene onwards (Goin et al. 2016).

\section{The EOB and the evolution of the NPP}

The isolation of Antarctica due to the widening of the Tasman Sea and the full opening of the Drake Passage by the Eocene-Oligocene boundary (EOB), produced a ring of cold marine waters around the continent. Under the influence of this ring, glaciation began in the Antarctic continent, and this glaciation marked (at least in mid- and high latitudes located north and south of the Equator) the end of the last phase of the so called Greenhouse World and the beginning of the Icehouse World (Hansen et al. 2013). Additionally, the global cooling recorded during the EOB has been explained by other two concurrent factors: a higher albedo, and the progressive closing of tropical oceanic gateways (Lawver and Gahagan 2003; Livermore et al. 2005). The flora established since the late Eocene in the middle and high latitudes of South America, was characterized by a peculiar mixture of elements with a current Austral-Antarctic distribution, together with others of Neotropical and Pantropical distribution, and others with a wide geographical distribution. This peculiar conformation of temperate-cold and warm elements 
led to its denomination as Paleoflora Mixta ('Mixed Paleoflora', Troncoso and Romero 1998). The climatic estimates derived from this flora, as well as the palynological assemblages recorded in deposits of the Fuegian Andes (Roselló et al. 2004) allow us to infer annual average temperatures and annual average rainfalls much lower than those of the early and middle Eocene (Villagrán and Hinojosa 2005), similar to those of the current dry forests of the Holdridge life zones (e.g., Lugo et al. 1999). The mentioned environmental changes appear to have triggered a major biotic turnover (Flynn et al. 2003; Goin et al. 2010), named the Bisagra Patagónica (the 'Patagonian Hinge'; Goin et al. 2010; 2012, 2016, in press), which represents in South America a regional expression of the Terminal Eocene Event. Among metatherians, this resulted in the demise of groups that had flourished during the Paleocene and Eocene, such as basal 'ameridelphians', Caroloameghiniidae (Didelphimorphia; Goin et al. 2016), Glasbiidae, Bonapartherioidea and Polydolopidae (Polydolpimorphia; Goin and Candela 2004; Chornogubsky 2010). Other metatherians groups radiated, giving rise to more modern lineages; among which there were the argyrolagoid polydolopimorphians (but see, Beck 2017), borhyaenid and hathliacynid sparassodontans (Forasiepi 2009), microbiotheriid microbiotherians (Goin and Abello 2013), and palaeothentoid paucituberculatans, which formed taxonomically different assemblages towards the end of the Paleogene and during the Neogene. The taxonomic diversity of metatherians sharply dropped near the EOB and, from an ecological point of view a functional turnover occurred, with its most notable aspects being the diversification of carnivorous (sparassodontans) and granivorous (argyrolagoid) types, and the decline of frugivores (Zimicz 2012; Goin et al. 2016). In this context, paucituberculatans were one of the metatherian groups that diversified more widely. However, across the EOB both components of diversity may be decoupled as taxonomic diversity increased while most disparity metrics evidenced non-significant change (Figure 4, Table 2, SM4.7). Occupied morphospace shows no significant range change between the Eocene and early Oligocene time bins (Figures 4 and 5; Table 2). These results may be due to morphologies that appeared in the initial diversification of the Abderitidae+Palaeothentidae clade, during the early Oligocene, compensating for the morphological diversity lost by the disappearance of Sasawatsu and Perulestes species at the end of the Eocene (Figure 5). On the other hand, the increasing taxonomic diversity of the NPP during the early Oligocene is mostly explained by the early cladogenesis of abderitids and palaeothentids (Figure 2). These paucituberculatans were successful in comparison to basal members of the NPP as they diversified during the Oligocene (see below) and became an important component of the micromammal assemblages during the Miocene (Marshall 1990; Bown and Fleagle 1993; Abello 2007; Rincón et al. 2015, Engelman et al. 2016).

\section{Evolution of the NPP in the aftermath of the EOB climatic events}

As mentioned in the previous paragraphs, the South American flora of the early Oligocene was similar to that of the late Eocene, with a progressive replacement of warm flora by a more temperate one, suggesting the existence of forests developed under abundant rainfalls (Barreda and Palazzesi 2010). Late Oligocene plant communities in Patagonia were characterized by a marked presence of groups with herbaceous-shrubby habits (Barreda and Palazzesi 2010), while xerophytic species would have occupied coastal salt marsh environments and open patches in internal areas, probably as a consequence of volcanic activity (Barreda and Palazzesi 2007). However, closed forests were still present in extra-Andean Patagonia (Barreda and Palazzesi 2010). This allows us to infer the establishment of a marked floristic contrast between the continental and coastal environments (Barreda and Palazzesi 2007).

The climatic-environmental inferences derived from mammals are congruent with botanical ones. The early Oligocene land-mammal communities were dominated by the browsers, but mixed-feeders and 'grazers' were more diverse than during the Eocene (Ortiz-Jaureguizar and Cladera 2006). This is compatible with the existence of wooded savannas, developed within a low annual rainfall regime. In the late Oligocene, and for the first time during the Cenozoic, the land-mammal communities become dominated by 'grazers', although browsers and frugivores still showed a high diversity (OrtizJaureguizar and Cladera 2006). The predominance of mammals with hypsodont/hypselodont molars suggests that the open habitats had a wide areal distribution in central Patagonia during the late Oligocene. This new distribution of trophic types is compatible with a wooded savanna vegetation, although somewhat more open than that of the early Oligocene (Pascual et al. 1996).

From the early to the late Oligocene, the taxonomic diversity of NPP continued to increase, and, in contrast to the previous time interval, disparity experienced a significant increase, reaching its highest values towards the late Oligocene (Figure 4, Table 1). The concordant expansion of both components of the diversity suggests a gradual occupation of morphospace with no apparent constraint on morphological diversity (Erwin 2007). This pattern could be explained by the evolution of the NPP in an empty ecospace. Considering the ecospace hypothesis (see Erwin 1993, 1994), the release of ecological interactions following the extinctions at the EOB, as well as the availability of new resources, would have been key for novel morphologies emerged among NPP to become successful, allowing subsequent diversification. As expressed above, several metatherian lineages disappeared at the end of the Eocene (e.g. basal 'ameridelphians') or at the beginning of the Oligocene (e.g. polydolopids). Polydolopids and abderitids have a similar plagiaulacoid type of dentition and it has been proposed that they must have had a similar ecological role (Ortiz-Jaureguizar 2003). They potentially coexisted during the early Oligocene, as the reconstructed earliest lineages of abderitids were coeval with the last recorded polydolopid. However, the last registered polydolopids were relatively large metatherians, the largest one having a body mass of $3.5 \mathrm{~kg}$ (Zimicz 2012; Goin et al. in press) represented the end of a trend to size increase in this group (Goin et al. 2016), while the reconstructed body mass of the first abderitids was between 284-391g (Figure 2). Therefore, abderitids and polydolopids hardly competed then nor did abderitids opportunistically replaced polydolopids; rather it appears that abderitids 
diversified because new ecological opportunities were generated by the vacancy left by the demise of other small-sized marsupials (e.g. Caroloameghiniidae, Zimicz 2012), and/or due to the availability of new resources. In extant marsupials with dental shearing complexes similar to those of abderitids (e.g. the burramyid Burramys, the hypsiprymnodontid Hypsiprymnodon and the potoroid Bettongia; Figure 1D-F), these dental modifications have been observed to be well-adapted to deal with diverse food items bearing hard coverings (e.g., insects and seeds), and they are associated with different dietary types, ranging from insectivore-frugivore and mostly frugivorore to fungivoreomnivore (Dimpel and Calaby 1972; Seebeck and Rose 1989; Strahan 1995). Regarding these ecological data, it is possible that, as was suggested by Dumont et al. (2000), abderitids were dietary generalists since their derived dental complex would allow them to have access to a wide range of food items. Thus, as climatic-environmental conditions were changing, such dental modifications could have been advantageous for the abderitids to exploit new food resources.

In contrast to the lophodont molars and the specialized plagiaulacoid dentition of abderitids, palaeothentids developed more crested molars, with crests not particularly transverse as in abderitids, and an enlarged first lower molar with a less emphasized shearing crest (Marshall 1980; Bown and Fleagle 1993; Abello 2013; Figure 1B-C). Among palaeothentids, the derived characters of acdestines that differentiate them from their sister group, the palaeothentines, include a longer shearing crest in the first lower molar, a quite reduced third lower premolar and a marked decrease in size from the first to the last molar (Bown and Fleagle 1993; Abello 2013; Figure 1C). Therefore, besides that of abderitids, two dental morphologies each characterizing the major clades of palaeothentids, appeared during the early Oligocene. Inferred diets for abderitids range from insectivore-frugivore, in the small Pitheculites minimus, to frugivore in the larger Abderites meridionalis. On the other hand, reconstructed dietary preferences of palaeothentids were broader, also including insectivory (Dumont et al. 2000), and probably also the opportunistic consumption of small vertebrates (Engelman et al. 2016). The various feeding habits reconstructed for palaeothentids coupled with the fact that they lacked a welldeveloped shearing complex led to Dumont et al. (2000) to consider palaeothentids as dietary specialists. Despite the fact that the ecological diversity of palaeothentids is mostly known from the Miocene fossil record, it can be inferred that it began to expand, as did their taxonomic diversity, during the Oligocene. By the late Oligocene, palaeothentids showed roughly twice the phylogenetically corrected diversity of abderitids (Table 1). Taking into account the climaticenvironmental changes occurred near the EOB, it seems probable that, as in abderitid evolution, changing ecological conditions could have shaped the palaeothentid radiation, promoting extensive cladogenesis and ecological divergence among lineages.

From the Miocene, the tectonic activity becomes more important in the continent, as a consequence of the increase in the subduction rate between the South American and Nazca plates and the progressive raising of the Andes. The orographic change associated with this greater tectonic activity had a remarkable climatic and biotic impact in South America: it generated the marked contrast existing between the wet western and arid eastern environments of the southernmost part of the continent, as a result of the differentiation of the Andean region as a barrier to the wet winds from the Pacific Ocean (see Villagrán and Hinojosa 2005; Ortiz-Jaureguizar and Cladera 2006; Pascual and OrtizJaureguizar 2007). During the early Miocene, the geologicalgeographical features of the continent were similar to those of the late Oligocene. However, at the end of this period, an explosive volcanism registered from central Patagonia to the Strait of Magellan injected into the atmosphere a high amount of volcanic ash, which gave rise to the thick deposits of tuffs that represents this time in Patagonia. Also, during this time a new Antarctic glaciation was recorded, and a welldefined climatic seasonality was established in Patagonia (Ortiz-Jaureguizar and Cladera 2006). Until the final part of the early Miocene, sea levels remained relatively low and temperatures remained relatively constant (Markgraf et al. 1996).

The flora of the early Miocene showed pulses of advance and retreat of the indicator communities of arid and humid climates (Barreda and Palazzesi 2010). The phytoliths continued to indicate a predominance of the arboreal vegetation, but with an increase of grasses of open zones. This has been interpreted as an indicator of the enduring existence of forests with open areas with grasses, or the existence of temporary variations due to seasonality, aridity or other environmental factors that damage the forests at certain times of the year and favour grasses (Strömberg et al. 2013). The early Miocene land-mammal fauna was similar to that of the late Oligocene, i.e., dominated by the 'grazers' but with a high diversity of browsers and frugivores. The main difference between both faunas is the greater number of mixed-feeders in the early Miocene, which indicates that during this time there was a balance between the open habitats and the forests, probably represented by park-savannah formations. The record of primates and other climate-sensitive vertebrates (such as frogs and anteaters) in latitudes as high as southern Patagonia, suggests that warm and humid climates, as well as forested formations, were well developed in Patagonia (see Kay et al. 2012). Together with these records, the diversity of some mammals adapted to open vegetation and drier climates [e.g., relative richness of dasypodid xenarthrans (see Vizcaíno et al. 2006, 2012), some caviomorph rodents such as eocardiids and dasyproctids (e.g., Candela et al. 2012)] suggest the existence of climatic events of greater aridity or complex environments represented by a mixture of closed and open plant formations (Pascual et al. 1996; Ortiz-Jaureguizar and Cladera 2006; Kay et al. 2012).

From the late Oligocene to the early Miocene, the taxonomic diversity of NPP continued increasing while disparity did not exhibit a clear change or even decreased, thus becoming again decoupled in some extent (Figure 4, Table 2, SM4.7). This pattern could be partially explained by the extinction of the Pilchenia and the Antahuallathentes-Carlothentes clades during the late Oligocene (Figure 2). However, the macroevolutionary pattern of both components of diversity from the late Oligocene to the Miocene is also compatible with the NPP having reached 
certain constraints in their morphological evolution. It has been stated that in certain models of evolution, cladogenesis may progress up to some limits to form are reached, after which new lineages emerge as variations of the primary morphotypes filling in the gaps of the morphospace (Foote 1994; WesleyHunt 2005; Brusatte et al. 2010; Benton et al. 2014). Considering this model, the high Miocene taxonomic diversity of NPP can be seen as the result of a lineage proliferation within certain morphological bounds set in the Oligocene (i.e., those characterizing abderitids, palaeothentines and acdestines, see above). As shown by the morphospace occupation, Miocene species of the Abderites-Pitheculites and Palaeothentes clades constitute clumps. It appears that new lineages of NPP emerged in Miocene times by evolving minor differences in dental morphology and accentuated body size differences (Figure 2). This could be the case of Palaeothentes cladogenesis, a clade that includes almost half of the NPP species known from the Miocene. Palaeothentes species are quite similar dentally and they mainly differ in body size. In the late early Miocene of southern South America (Santa Cruz Formation; Vizcaíno et al. 2012), five Palaeothentes species coexisted ranging in body mass from $45 \mathrm{~g}$ ( $P$. pascuali) to $981 \mathrm{~g}$ ( $P$. aratae). Except for the frugivore $P$. aratae, remaining species were insectivores $(P$. pascuali, $P$. minuntus, $P$. intermedius, and P. lemoinei; Dumont et al. 2000). It was suggested that body size differences evolved among insectivore species of Palaeothentes allowing niche separation as occur in extant insectivore assemblages of dasyurid marsupials and soricid placentals (Abello et al. 2012). In addition, considering the diverse small-sized non carnivorous metatherians coexisting in Santacrucian assemblages, it was proposed that certain niche partitioning in the vertical dimension could not be ruled out. In this sense, in addition to the terrestrial curso-saltatorial P. minutus and P. lemoinei (Abello \& Candela 2010; Forasiepi et al. 2014), NPP species may have had other substrate uses as arboreal or scansorial habits. This differential use of space would have allowed the coexistence of several marsupial species minimizing competition, as happens in extant ecosystems (Charles-Dominique et al. 1981; Charles Dominique 1983; Vieira and Monteiro-Filho 2003; Ernest 2013).

\section{Conclusions}

The Eocene-Oligocene boundary marks a period of remodeling of the South American metatherian assemblages. The changes in climatic-environmental conditions that occurred since then affected groups differently; while some of them declined and went extinct, others such as non-pichipilid paucituberculatans, diversified probably by the exploitation of new ecological opportunities.

Non-pichipilid paucituberculatans experienced a wide radiation, with an extensive cladogenesis and ecological diversification, which can be recognized by contrast with the evolutionary history of its sister clade Pichipilidae and the Caenolestidae. In all macroevolutionary parameters analyzed, i.e., taxonomic diversity, disparity and body mass range, the NPP reached values significantly higher than those of the remaining paucituberculatan clades.

Tracking the taxonomic diversity and disparity of NPP through time, was observed that each analyzed transition among time bins (middle-late Eocene to early Oligocene; early Oligocene to late Oligocene; late Oligocene to early Miocene) was characterized by different macroevolutionary patterns. From the initial radiation in the middle Eocene, taxonomic diversity increased through time, although it was decoupled from disparity from the middle-late Eocene until the early Oligocene, and then, from the late Oligocene until early Miocene. The Oligocene was the most important time in the evolution of the NPP, since this was when a significant and concordant expansion in disparity and taxonomic diversity occurred. This evolutionary response appears to have been triggered by the evolution in an empty ecospace. At that time, three different dental morphologies emerged, each one characterizing the main NPP clades: Abderitidae, Palaeothentinae and Acdestinae, and major cladogenetic events occurred in the Abderites-Pitheculites and Palaeothentidae clades. In addition, at the end of this epoch, and during the Miocene, they evolved a wide range of body masses that reflects an important ecological diversification. The increased taxonomic diversity from the late Oligocene to early Miocene and concurrent decrease in disparity during this temporal transition was probably the result of a wide diversification constrained within a given morphology. Among the NPP, the abderitid and palaeothentid clades followed different patterns of diversification. Palaeothentids were more speciose than abderitids at any time, and the latter reached their highest taxonomic diversity earlier (late Oligocene) than palaeothentids (early Miocene). These different patterns may be due to, as was proposed earlier (Dumont et al. 2000), the condition of dietary generalist (abderitids) or specialist (palaeothentids) of the species of each major NPP group.

\section{Acknowledgments}

We are grateful to Robin M. D. Beck and an anonymous reviewer who provided critical discussions and constructive suggestions that improved the final manuscript. We thanks to G.H. Cassini (MACN-CONICET) for his help with programming of jack-knifing function in $\mathrm{R}$. This research was supported by a grant from CONICET (PIP 0446).

\section{Disclosure statement}

No potential conflict of interest was reported by the authors.

\section{References}

Abello MA 2007. Sistemática y bioestratigrafía de los Paucituberculata (Mammalia, Marsupialia) del Cenozoico de América del Sur. Thesis, Universidad Nacional de La Plata. Available at: http://naturalis.fcnym. unlp.edu.ar/id/20120126000025

Abello MA, Ortiz-Jaureguizar E, Candela AM. 2012. Paleoecology of the Paucituberculata and Microbiotheria (Mammalia, Marsupialia) from the late early Miocene of Patagonia. In: Vizcaíno SF, Kay RF, Bargo MS, editors. Early Miocene paleobiology in Patagonia: high-latitude paleocommunities of the Santa Cruz Formation. Cambridge: Cambridge University Press; p. 156-172.

Abello MA. 2013. Analysis of dental homologies and phylogeny of Paucituberculata (Mammalia: marsupialia). Biol J Linnean Soc. 109:441-465.

Abello MA, Candela AM. 2010. Postcranial skeleton of the Miocene marsupial Palaeothentes (Paucituberculata, Palaeothentidae): paleobiology and phylogeny. J Verteb Paleontol. 30:1515-1527. 
Abello MA, Posadas P, Ortiz-Jaureguizar E 2010. Biogeografía histórica de los Caenolestidae (Marsupialia, Paucituberculata) del Cenozoico de América del Sur. $X$ Congreso Argentino de Paleontología $y$ Bioestratigrafía y VII Congreso Latinoamericano de Paleontología, Actas R189: 128.

Abello MA, Toledo N, Ortiz-Jaureguizar E. 2015. Evolución del tamaño corporal y radiación evolutiva de los Paucituberculata (Mammalia: marsupialia) durante el Cenozoico de América del Sur. Reunión de Comunicaciones de la Asociación Paleontológica Argentina (RCAPA 2015), Mar del Plata. Ameghiniana. 53(4). Suplemento, Resúmenes: 3. 2016.

Abello MA, Toledo N, Ortiz-Jaureguizar E 2016. Análisis de la diversidad morfológica de los Paucituberculata (Mammalia: marsupialia) durante el Cenozoico de América del Sur. XI Congreso de la Asociación Paleontológica Argentina, Roca. Resúmenes Pp. 23-24.

Abouheif E. 1999. A method for testing the assumption of phylogenetic independence in comparative data. Evol Ecol Res. 1:895-909.

Albuja L, Patterson BD. 1996. A new species of northern shrew-opossum (Paucituberculata: caenolestidae) from the Cordillera del Cóndor, Ecuador. J Mammal. 77:41-53.

Amador LI, Giannini NP. 2016. Phylogeny and evolution of body mass in didelphid marsupials (Marsupialia: didelphimorphia: didelphidae). Organisms Divers Evol. 16:641-657.

Antoine PO, Abello MA, Adnet S, Sierra AJA, Baby P, Billet G, Boivin M, Calderon Y, Candela MA, Chabain J, et al. 2016. A 60-million-year Cenozoic history of western Amazonian ecosystems in Contamana, eastern Peru. Gondwana Res. 31:30-59.

Bapst DW. 2012. Paleotree: an R package for paleontological and phylogenetic analyses of evolution. Methods Ecol Evol. 3:803-807.

Barreda V, Palazzesi F. 2010. Vegetation during the Eocene-miocene interval in central Patagonia: a context of mammal evolution. In: Madden RH, Carlini AA, Vucetich MG, Kay RF, editors. The Paleontology of Gran Barranca. New York: Cambridge University Press; p. 375-382.

Barreda V, Palazzesi F. 2007. Patagonian vegetation turnovers during the Paleogene-Early Neogene: origin of arid-adapted floras. Bot Rev. 73:31-50.

Beck RMD. 2017. The skull of Epidolops ameghinoi from the early Eocene Itaboraí fauna, southeastern Brazil, and the affinities of the extinct marsupialiform order Polydolopimorphia. J Mamm Evol. 24:373-414.

Benson RB, Evans M, Druckenmiller PS. 2012. High diversity, low disparity and small body size in plesiosaurs (Reptilia, Sauropterygia) from the Triassic-jurassic boundary. PLoS One. 7(3):e31838.

Benton MJ, Forth J, Langer MC. 2014. Models for the rise of the dinosaurs. Curr Biol. 24(2):R87-R95.

Bond M, Tejedor MF, Campbell KE Jr, Chornogubsky L, Novo N, Goin FJ. 2015. Eocene primates of South America and the African origins of New World monkeys. Nature. 520(7548):538-541.

Bown TM, Fleagle JG. 1993. Systematics, biostratigraphy, and dental evolution of the Palaeothentidae, later Oligocene to early-middle Miocene (Deseadan-Santacrucian) caenolestoid marsupials of South America. J Paleontol. 67(Suppl. 2):1-76.

Brusatte SL, Benton MJ, Lloyd GT, Ruta M, Wang SC. 2010. Macroevolutionary patterns in the evolutionary radiation of archosaurs (Tetrapoda: diapsida). Earth Environ Sci Trans Royal Soc Edinburgh. 101(3-4):367-382.

Brusatte SL, Benton MJ, Ruta M, Lloyd GT. 2008a. Superiority, competition, and opportunism in the evolutionary radiation of dinosaurs. Science. 321:1485-1488.

Brusatte SL, Benton MJ, Ruta M, Lloyd GT. 2008b. The first 50 Myr of dinosaur evolution: macroevolutionary pattern and morphological disparity. Biol Lett. 4(6):733-736.

Brusatte SL, Montanari S, Yi H-Y, Norell MA. 2011. Phylogenetic corrections for morphological disparity analysis: new methodology and case studies. Paleobiology. 37:1-22.

Candela AM, Rasia LL, Pérez ME. 2012. Paleobiology of Santacrucian caviomorph rodents: a morphofunctional approach. In: Vizcaíno SF, Kay RF, Bargo MS, editors. Early Miocene paleobiology in Patagonia: high-latitude paleocommunities of the Santa Cruz Formation. Cambridge: Cambridge University Press; p. 287-305.
Charles Dominique P. 1983. Ecology and social adaptation in didelphid marsupials: comparisons with eutherians of similar ecology. In: Eisenberg JF, editor. Advances in the Study of Mammalian Behavior, Vol. 7. Shippensburg, Pennsylvania: American Society of Mammalogists Special Publication; p. 305-422.

Charles-Dominique $\mathrm{P}$, Atramentowicz $\mathrm{M}$, Charles-Dominique $\mathrm{M}$, Gerard H, Hladik A, Hladik CM, Prévost MF. 1981. Les mammiferes frugivores arboricoles nocturnes d'une foret guyanaise: inter-relations plantes- animaux. Revue d'Ecologie (Terre Vie). 35:341-436.

Chornogubsky L 2010. Sistemática de la familia Polydolopidae (Mammalia, Marsupialia, Polydolopimorphia) de América del Sur y la Antártica. Thesis, Universidad Nacional de Buenos Aires.

Ciampaglio CN, Kemp M, McShea DW. 2001. Detecting changes in morphospace occupation patterns in the fossil record: characterization and analysis of measures of disparity. Paleobiology. 27(4):695-715.

Damuth JD, MacFadden BJ. 1990. Introduction: body size and its estimation. In: Damuth J, MacFadden BJ, editors. Body Size in Mammalian Paleobiology: estimation and Biological Implications. New York: Cambridge University Press; p. 1-10.

Dimpel H, Calaby JH. 1972. Further observations on the mountain pygmy-possum (Burramys parvus). Victorian Naturalist. 89:101-106.

Dray S, Dufour AB. 2007. The ade4 package: implementing the duality diagram for ecologists. J Stat Softw. 22(4):1-20.

Dumont ER, Strait SG, Friscia AR. 2000. Abderitid marsupials from the Miocene of Patagonia: an assessment of form, function, and evolution. J Paleontol. 74:1161-1172.

Engelman RK, Anaya F, Croft DA. 2016. New palaeothentid marsupials (Paucituberculata) from the middle Miocene of Quebrada Honda, Bolivia, and their implications for the palaeoecology, decline and extinction of the Palaeothentoidea. Journal of Systematic. Palaeontology. 15(10):787-820.

Ernest SKM. 2013. Using size distributions to understand the role of body size in mammalian community assembly. In: Smith FA, Lyons SK, editors. Animal Body Size: linking pattern and process across space, time and taxonomic group. Chicago: The University of Chicago Press; p. 146-167.

Erwin DH. 1993. Early introduction of major morphological innovations. Acta Palaeontol Pol. 38:3-4.

Erwin DH. 1994. Major morphologic innovations. Acta Palaeontol Pol. 38:281-294.

Erwin DH. 2007. Disparity: morphological pattern and developmental context. Palaeontology. 50(1):57-73.

Flynn JJ, Wyss AR, Croft DA, Charrier R. 2003. The Tinguiririca Fauna, Chile: biochronology, paleoecology, biogeography, and a new earliest Oligocene South American Land Mammal Age. Palaeogeogr Palaeoclimatol Palaeoecol. 195:229-259.

Foote M. 1993a. Contributions of individual taxa to overall morphological disparity. Paleobiology. 19(04):403-419.

Foote M. 1993b. Discordance and concordance between morphological and taxonomic diversity. Paleobiology. 19(02):185-204.

Foote M. 1994. Morphological Disparity in Ordovician-Devonian Crinoids and the Early Saturation of Morphological Space. Paleobiology. 20(3):320-344.

Foote M. 1997. The evolution of morphological diversity. Annu Rev Ecol Syst. 28:129-152.

Forasiepi AM. 2009. Osteology of Arctodictis sinclairi (Mammalia, Metatheria, Sparassodonta) and phylogeny of Cenozoic metatherian carnivores from South America. Monografías Del Museo Argentino De Ciencias Naturales NS. 6:1-174.

Forasiepi AM, Sánchez-Villagra MR, Schmelzle T, Ladevèze S, Kay RF. 2014. An exceptionally well-preserved skeleton of Palaeothentes from the Early Miocene of Patagonia, Argentina: new insights into the anatomy of extinct paucituberculatan marsupials. Swiss J Palaeontol. 133(1):1-21.

Frailey CD, Campbell KE Jr. 2004. Paleogene rodents from Amazonian Peru: the Santa Rosa local fauna. Sci Ser Natural Hist Museum Los Angeles County. 40:71-130.

Giannini NP, Gunnell GF, Habersetzer J, Simmons NB. 2012. Early evolution of body size in bats. In: Gunnell GF, Simmons NB, editors. 
Evolutionary history of bats: fossils, molecules, and morphology. Cambridge: Cambridge University Press; p. 530-555.

Goin FJ, Abello MA, Chornogubsky L. 2010. Middle Tertiary marsupials from central Patagonia (early Oligocene of Gran Barranca): understanding South America's Grande Coupure. In: Madden RH, Carlini AA, Vucetich MG, Kay RF, editors. The Paleontology of Gran Barranca: evolution and Environmental Change through the Middle Cenozoic of Patagonia. Cambridge: Cambridge University Press; p. 69-105.

Goin FJ, Gelfo JN, Chornogubsky L, Woodburne MO, Martin T. 2012. Origins, radiations, and distribution of South American mammals: from greenhouse to icehouse worlds. In: Patterson BD, Costa LP, editors. Bones, clones, and biomes: an 80-million year history of Recent Neotropical mammals. Chicago: The University of Chicago Press; p. 20-50.

Goin FJ, Zimicz AN, Forasiepi AM, Chornogubsky LC, Abello MA. in press. The rise and fall of South American metatherians: contexts, adaptations, radiations, and extinctions. In: Rosenberger AL, Tejedor MF, editors. Origins and Evolution of Cenozoic South American Mammals. New York: Springer Verlag.

Goin FJ, Abello MA. 2013. Los Metatheria sudamericanos de comienzos del Neógeno (Mioceno temprano, edad-mamífero Colhuehuapense. Parte II: microbiotheria y Polydolopimorphia. Ameghiniana. 50:51-78.

Goin FJ, Candela AM. 2004. New Paleogene marsupials from the Amazon Basin of Eastern Peru. Sci Ser Natural Hist Museum Los Angeles County. 40:15-60.

Goin FJ, Candela AM, Abello MA, Oliveira EV. 2009. Earliest South American paucituberculatans and their significance in the understanding of 'pseudodiprotodont' marsupial radiations. Zool J Linn Soc. 155:867-884.

Goin FJ, Woodburne MO, Zimicz AN, Martin GM, Chornogubsky L. 2016. A brief history of South American metatherians: evolutionary contexts and intercontinental dispersals. New York: Springer; p. 237.

Goloboff P, Farris S, Nixon K. 2003. TNT: Tree analysis using New Technology. Program and documentation, available from authors. [accessed 2017 July 26]. http://www.lillo.org.ar/phylogeny/tnt/.

Gordon CL. 2003. A first look at estimating body size in dentally conservative marsupials. J Mamm Evol. 10(1-21):(1-2).

Gould GC, MacFadden BJ. 2004. Gigantism, dwarfism, and Cope's rule: bnothing in evolution makes sense without a phylogeny. Bull Am Museum Nat Hist. 285:219-237.

Gould SJ. 1991. The disparity of the Burgess Shale arthropod fauna and the limits of cladistic analysis: why we must strive to quantify morphospace. Paleobiology. 17(04):411-423.

Hansen J, Sato M, Russell G, Kharecha P. 2013. Climate sensitivity, sea level and atmospheric carbon dioxide. Philos Trans R Soc London A. 371(2001):20120294.

Harmon LJ, Weir JT, Brock CD, Glor RE, Challenger W. 2008. GEIGER: investigating evolutionary radiations. Bioinformatics. 24:129-131.

Hoorn C, Wesselingh FP, Ter Steege H, Bermudez MA, Mora A, Sevink J, Sanmartín I, Sanchez-Meseguer A, Anderson CL, Figueiredo JP, et al. 2010. Amazonia through time: andean uplift, climate change, landscape evolution, and biodiversity. Science. 330(6006):927-931.

Jaramillo C, Rueda MJ, Mora G. 2006. Cenozoic plant diversity in the Neotropics. Science. 311(5769):1893-1896.

Jombart T, Balloux F, Dray S. 2010. adephylo: new tools for investigating the phylogenetic signal in biological traits. Bioinformatics. 26 (15):1907-1909.

Kay RF, Vizcaíno SF, Bargo MS. 2012. A review of the paleoenvironment and paleoecology of the Miocene Santa Cruz Formation. In: Vizcaíno SF, Kay RF, Bargo MS, editors. Early Miocene paleobiology in Patagonia: high-latitude paleocommunities of the Santa Cruz Formation. Cambridge: Cambridge University Press; p. 331-365.

Keck F, Rimet F, Bouchez A, Franc A. 2016. phylosignal: an R package to measure, test, and explore the phylogenetic signal. Ecol Evol. 6 (9):2774-2780.

Kirsch JAW, Waller PF. 1979. Notes on the trapping and behavior of the Caenolestidae (Marsupialia). J Mammal. 60:390-395.

Lane A, Janis CM, Sepkoski JJ. 2005. Estimating paleodiversities: a test of the taxic and phylogenetic methods. Paleobiology. 31:21-34.
Lawver LA, Gahagan LM. 2003. Evolution of Cenozoic seaways in the circum-Antarctic region. Palaeogeogr Palaeoclimatol Palaeoecol. 198:11-37.

Livermore R, Nankivell A, Eagles G, Morris P. 2005. Paleogene opening of drake passage. Earth Planet Sci Lett. 236:459-470.

Lloyd GT. 2016. Estimating morphological diversity and tempo with discrete character-taxon matrices: implementation, challenges, progress, and future directions. Biol J Linnean Soc. 118:131-151.

Lugo AE, Brown SL, Dodson R, Smith TS, Shugart HH. 1999. The Holdridge life zones of the conterminous United States in relation to ecosystem mapping. J Biogeogr. 26:1025-1038.

Malumian N, Nañez C. 2011. The Late Cretaceous-Cenozoic transgressions in Patagonia and the Fuegian Andes: foraminifera, palaeoecology, and palaeogeography. Biol J Linnean Soc. 103(2):269-288.

Markgraf V, Romero E, Villagrán C. 1996. History and paleoecology of South American Nothofagus forests. In: Veblen TT, Hill RS, editors. The Ecology and Biogeography of Nothofagus Forests. New Haven: Yale University Press; p. 354-386.

Marshall LG. 1980. Systematics of the South American marsupial family Caenolestidae. Fieldiana Geol New Ser. 5:1-145.

Marshall LG. 1990. Fossil Marsupialia from the type Friasian Land Mammal Age (Miocene), Alto Río Cisnes, Aisen, Chile. Revista Geológica De Chile. 17:19-55.

Martin GM, González-Chávez B. 2016. Observations on the behavior of Caenolestes fuliginosus (Tomes, 1863) (Marsupialia, Paucituberculata, Caenolestidae) in captivity. J Mammal. 97:568-575.

Münkemüller T, Lavergne S, Bzeznik B, Dray S, Jombart T, Schiffers K, Thuiller W. 2012. How to measure and test phylogenetic signal. Methods Ecol Evol. 3:743-756.

Myers TJ. 2001. Prediction of marsupial body mass. Aust J Zool. 49:99-118.

Norell MA. 1992. Taxic origin and temporal diversity: the effect of phylogeny. In: Novacek MJ, Wheeler QD, editors. Extinction and phylogeny. New York: Columbia University Press; p. 89-118.

Norell MA. 1993. Tree-based approaches to understanding history; comments on ranks, rules and the quality of the fossil record. Am J Sci. 293:407-417.

Ojala-Barbour R, Pinto CM, Brito MJ, Albuja VL, Lee TE, Patterson BD. 2013. A new species of shrew-opossum (Paucituberculata: caenolestidae) with a phylogeny of extant caenolestids. J Mammal. 94:967-982.

Oliveira EV, Goin FJ. 2011. A reassessment of bunodont metatherians from the Paleogene of Itaboraí (Brazil): systematics and age of the Itaboraian SALMA. Revista Brasileira De Paleontología. 14:105-136.

Ollier S, Couteron P, Chessell D. 2006. Orthonormal transform to decompose the variance of a life-history trait across a phylogenetic tree. Biometrics. 62(2):471-477.

Ortiz-Jaureguizar E. 2003. Relaciones de similitud, paleoecología y extinción de los Abderitidae (Marsupialia, Paucituberculata). Coloquios De Paleontología, Volumen Extraordinario. 1:475-498.

Ortiz-Jaureguizar E, Cladera GA. 2006. Paleoenvironmental evolution of southern South America during the Cenozoic. J Arid Environ. 66 (3):498-532.

Paradis E. 2006. Analysis of Phylogenetics and Evolution with R. 2nd ed. New York: Springer; p. 401.

Paradis E, Claude J, Strimmer K. 2004. APE: analyses of phylogenetics and evolution in R language. Bioinformatics. 20:289-290.

Pascual R, Ortiz Jaureguizar E. Prado J.L. 1996. Land mammals: paradigm for Cenozoic South American geobiotic evolution. Münchner Geowissenschaftliche Abhandlungen. 30(A):265-319.

Pascual R, Ortiz-Jaureguizar E. 2007. The Gondwanan and South American episodes: two major and unrelated moments in the history of the South American mammals. J Mamm Evol. 14(2):75-137.

Patterson BD. 2007. Order Paucituberculata Ameghino, 1894. In: Gardner AL, editor. Mammals of South America, Vol. 1, Marsupials, Xenarthrans, Shrews, and Bats. Chicago and London: University of Chicago Press; p. 119-127.

Patterson BD, Gallardo MH. 1987. Rhyncholestes raphanurus. Mamm Species. 286:1-5.

Pavoine S, Ollier S, Pontier D, Chessel D. 2008. Testing for phylogenetic signal in phenotypic traits: new matrices of phylogenetic proximities. Theor Popul Biol. 73(1):79-91. 
Prevosti FJ, Forasiepi AM, Zimicz AN. 2013. The evolution of the Cenozoic terrestrial mammalian predator guild in South America: competition or replacement? J Mamm Evol. 20:3-21.

R Core Team (2017). R: A language and environment for statistical computing. R Foundation for Statistical Computing, Vienna (Austria). [accessed 2017 November 1]. URL https://www.R-project.org/

Ramos VA, Ghiglione MC. 2008. Tectonic evolution of the Patagonian Andes. Dev Quaternary Sci. 11:57-71.

Rincón AD, Shockey BJ, Anaya F, Solórzano A. 2015. Palaeothentid marsupials of the Salla Beds of Bolivia (late Oligocene): two new species and insights into the post-Eocene radiation of palaeothentoids. J Mamm Evol. 22:455-471.

Roselló EA, Ottone EG, Haring CE, Nevistic VA. 2004. Tectonic and paleoenvironmental significance of the Paleogene coal seams of Estancia La Correntina, Fuegian Andes. Revista De La Asociación Geológica Argentina. 59:778-784.

Rougier GW, Wible JR, Novacek MJ. 1998. Implications of Deltatheridium specimens for early marsupial history. Nature. 396:459-463.

Schluter D. 2000. 2000. The ecology of adaptive radiation. Oxford: Oxford University Press.

Seebeck JH, Rose RW. 1989. Potoroidae. In: Walton DW, Richardson BJ, editors. Fauna of Australia Vol. 1B: mammalia. Canberra: Australian Government Publishing Service; p. 716-739.

Simpson GG. 1933. The "Plagiaulacoid" type of mammalian dentition. J Mammal. 14(2):97-107.

Simpson GG. 1953. The Major Features of Evolution. New York: Columbia Univ. Press; p. 434.

Smith RJ. 1993. Logarithmic transformation bias in allometry. Am J Phys Anthropol. 90:215-228.

Strahan R. 1995. Mammals of Australia. Washington: Smithsonian Institution Press; p. 756 p.

Strömberg CAE, Dunn RE, Madden RH, Kohn MJ, Carlini AA. 2013. Decoupling the spread of grasslands from the evolution of grazer-type herbivores in South America. Nat Commun. 4:1478.

Swofford DL, Maddison WP. 1987. Reconstructing ancestral character states under Wagner parsimony. Math Biosci. 87:199-229.

Troncoso A, Romero EJ. 1998. Evolución de las comunidades florísticas en el extremo sur de Sudamérica durante el Cenofítico. In: Fortunato $\mathrm{R}$, Bacigalupo $\mathrm{N}$, editors. Proceedings of the Congreso Latinoamericano de Botánica, Vol. 6. St. Louis: Monographs in Systematic Botany from the Missouri Botanical Garden; p. 149-172.

Vieira EM, Monteiro-Filho ELA. 2003. Vertical stratification of small mammals in the Atlantic rain forest of south-eastern Brazil. J Trop Ecol. 19:501-507.

Villagrán C, Hinojosa LF. 2005. Esquema biogeográfico de Chile. In: Llorente-Bousquets J, Morrone JJ, editors. Regionalización Biogeográfica en Iberoamérica y tópicos afines. México D.F.: Universidad Nacional Autónoma de México, Jiménez Editores; p. 551-577.

Vizcaíno SF, Kay RF, Bargo MS. 2012. Background for a paleoecological study of the Santa Cruz Formation (late Early Miocene) on the
Atlantic Coast of Patagonia. In: Vizcaíno SF, Kay RF, Bargo MS, editors. Early Miocene Paleobiology in Patagonia: high-latitude Paleocommunities of the Santa Cruz Formation. Cambridge: Cambridge University Press; p. 1-22.

Vizcaíno SF, Bargo MS, Kay RF, Milne N. 2006. The armadillos (Mammalia, Xenarthra) of the Santa Cruz Formation (Early-Middle Miocene). An approach to their paleobiology. Palaeogeogr Palaeoclimatol Palaeoecol. 237:255-269.

Warnes GR, Bolker B, Gorjanc G, Grothendieck G, Korosec A, Lumley T, MacQueen D, Magnusson A, Rogers J \& others. 2015. gdata: various $\mathrm{R}$ Programming Tools for Data Manipulation. R package version 2.17.0. [accessed 2017 November 1]. https://CRAN.R-pro ject.org/package $=$ gdata

Wesley-Hunt GD. 2005. The morphological diversification of carnivores in North America. Paleobiology. 31(1):35-55.

Wilf P, Cúneo NR, Escapa IH, Pol D, Woodburne MO. 2013. Splendid and Seldom Isolated: the paleobiogeography of Patagonia. Annu Rev Earth Planet Sci. 41:561-603.

Wilf P, Johnson KR, Cúneo NR, Smith ME, Singer BS, Gandolfo MA. 2005. Eocene plant diversity at Laguna del Hunco and Río Pichileufú, Patagonia, Argentina. Am Naturalist. 165(6):634-650.

Wills MA. 1998. Crustacean disparity through the Phanerozoic: comparing morphological and stratigraphic data. Biol J Linnean Soc. 65(4):455-500.

Wills MA. 2001. Morphological disparity: a primer. In: Adrain JM, Edgecombe GD, Lieberman BS, editors. Fossils, phylogeny, and form: an analytical approach. New York, NY: Kluwer Academic/ Plenum Publishers; p. 55-144

Wills MA, Briggs DE, Fortey RA. 1994. Disparity as an evolutionary index: a comparison of Cambrian and Recent arthropods. Paleobiology. 20(02):93-130.

Woodburne MO, Goin FJ, Bond M, Carlini AA, Gelfo JN, López GM, Iglesias A, Zimicz AN. 2014. Paleogene land mammal faunas of South America; a response to global climatic changes and indigenous floral diversity. J Mamm Evol. 21(1):1-73.

Zachos J, Pagani M, Sloan L, Thomas E, Billups K. 2001. Trends, rhythms, and aberrations in global climate $65 \mathrm{Ma}$ to present. Science. 292:686-693.

Zachos JC, Dickens GR, Zeebe RE. 2008. An early Cenozoic perspective on greenhouse warming and carbon-cycle dynamics. Nature. 451 (7176):279-283.

Zimicz AN. 2011. Patrones de desgaste y oclusión en el sistema masticatorio de los extintos Argyrolagoidea (Marsupialia, Polydolopimorphia, Bonapartheriiformes). Ameghiniana. 48(3):358-379.

Zimicz AN 2012. Ecomorfología de los marsupiales paleógenos de América del Sur. Thesis, Universidad Nacional La Plata.

Zimicz AN. 2014. Paleoecología de los Bonapartherioidea (Marsupialia, Polydolopimorphia, Bonapartheriiformes). Ameghiniana. 51(2):106-128.

Zucol AF, Brea M, Bellosi ES. 2010. Phytolith studies in Gran Barranca (central Patagonia, Argentina): the middle-late Eocene. In: Madden RH, Carlini AA, Vucetich MG, Kay RF, editors. The Paleontology of Gran Barranca. New York: Cambridge University Press; p. 317-340. 